UNIVERSIDADE DE SÃO PAULO

FACULDADE DE MEDICINA DE RIBEIRÃO PRETO

DEPARTAMENTO DE IMAGENS MÉDICA, HEMATOLOGIA E ONCOLOGIA CLÍNICA

ANTÔNIO BRUNO ALVES DA SILVA

INVESTIGAÇÃO DOS EFEITOS DA FENFORMINA EM NEOPLASIAS

MIELOPROLIFERATIVAS

RIBEIRÃO PRETO

2020 


\title{
INVESTIGAÇÃO DOS EFEITOS DA FENFORMINA EM NEOPLASIAS MIELOPROLIFERATIVAS
}

\author{
Versão Corrigida \\ (Versão original encontra-se na unidade que aloja \\ o Programa de Pós-graduação) \\ Dissertação apresentada à Faculdade de \\ Medicina de Ribeirão Preto da Universidade de São \\ Paulo para obtenção do título de Mestre em \\ Ciências. A versão original encontra-se disponível \\ na Biblioteca Digital de Teses e Dissertações da USP \\ (BDTD). \\ Programa de Oncologia Clínica, Células- \\ Tronco e Terapia Celular. \\ Área de Concentração: Diferenciação \\ Celular Normal e Neoplásica \\ Orientadora: Prof. ${ }^{a}$ Dr. ${ }^{a}$ Fabíola Traina \\ Co-orientadora: Prof. ${ }^{a}$ Dr. ${ }^{a}$ Lorena Lôbo de
} Figueiredo Pontes

Ribeirão Preto 
Autorizo a reprodução total ou parcial deste trabalho, por qualquer meio convencional ou eletrônico, para fins de estudo e pesquisa, desde que citada a fonte.

\section{FICHA CATALOGRÁFICA}

\section{Faculdade de Medicina de Ribeirão Preto}

\section{Universidade de São Paulo}

Silva, Antônio Bruno Alves

Investigação do efeito fenformina em neoplasias mieloproliferativas Ribeirão Preto, 2020. 75 f.

Dissertação de mestrado apresentada à Faculdade de Medicina de Ribeirão Preto-USP.

Programa de Oncologia Clínica, Células-Tronco e Terapia Celular. Área de Concentração: Diferenciação Celular Normal e Neoplásica.

Orientadora: Traina, Fabíola

1. Policitemia Vera 2. JAK2 3. Biguanidas 4. Neoplasias mieloproliferativas clássicas 5. JAK2V617F 


\section{APOIO E SUPORTE FINANCEIRO}

Este trabalho foi realizado com o apoio financeiro das seguintes entidades e instituições:

- Coordenação de Aperfeiçoamento de Pessoal de Nível Superior - CAPES

- Fundação de Amparo à Pesquisa do Estado de São Paulo - FAPESP

- Conselho Nacional de Desenvolvimento Científico e Tecnológico (CNPq)

- Faculdade de Medicina de Ribeirão Preto da Universidade de São Paulo (FMRP)

- Fundação Hemocentro de Ribeirão Preto (FUNDHERP)

- Fundação de Apoio ao Ensino, Pesquisa e Assistência do Hospital das Clínicas da Faculdade de Medicina de Ribeirão Preto da Universidade de São Paulo (FAEPA)

- Instituto Nacional de Ciência e Tecnologia em Células-tronco e Terapia Celular (INCTC). 
Nome: SILVA, Antônio Bruno Alves

Título: Investigação dos efeitos da fenformina em neoplasias mieloproliferativas.

Dissertação apresentada à Faculdade de Medicina de Ribeirão Preto da Universidade de São Paulo para obtenção do título de Mestre em Ciências, Programa de Oncologia Clínica, Células-Tronco e Terapia Celular; Área de Concentração: Diferenciação Celular Normal e Neoplásica

Aprovado em:

Banca Examinadora

Prof. Dr.

Instituição:

Julgamento:

Assinatura:

Prof. Dr.

Instituição:

Julgamento:

Assinatura:

Prof. Dr.

Instituição:

Julgamento:

Assinatura: 


\section{AGRADECIMENTOS}

Acima de tudo agradeço a Deus por tudo prover, comandar, guiar e por não falhar.

Aos meus pais, Claucia Freitas e José Airton Junior, por todo o sacrifício feito por minha educação, pelos ensinamentos, pelo apoio e pela paciência. Agradeço a vocês por tudo o que fizeram para que eu tivesse oportunidade de cursar o ensino superior. Agradeço à minha família por estarem comigo e, mesmo de longe, me darem suporte e forças para continuar nessa caminhada.

À minha orientadora, Prof. ${ }^{a}$ Dr. ${ }^{a}$ Fabiola Traina, por antes de tudo ter acreditado em mim, ainda lá no Ceará, e ter me dado a oportunidade de transpassar a barreira do ensino privado para o público. Agradeço pela compreensão, oportunidade e confiança. Obrigado por toda orientação que me foi concedida até hoje e pela oportunidade de crescimento pessoal e profissional. Obrigado por todas as críticas, correções e sugestões. Todos os seus ensinamentos me ajudam a moldar meu perfil profissional e certamente os levarei por toda minha carreira.

Aos meus amigos e parceiros de pesquisa e laboratório, André Luiz Pinto, Bruna Alves Fenerich, Flávia Ramos Donaires, Jaqueline Cristina Fernandes, Juan Luiz CoelhoSilva, Letícia Marani, Maria Florência Tellechea, Natasha Peixoto Fonseca, Raissa Tristão e Virgínia Campos Silvestrini, com vocês tudo se torna mais dinâmico e a pesquisa se torna mais leve.

Aos funcionários do laboratório de hematologia Bárbara Santana, Elizabete Audinno (Bete), Fernanda Borges da Silva, Ivana Barizza, e Virgínia Lipoli.

À equipe do biotério do Laboratório de Estudos Experimentais em Animais (LEEA), do Hemocentro de Ribeirão Preto, principalmente à Cleide Lúcia Araújo Silva e Thamires Ongilio, por todos os treinamentos, auxílios e contribuições para o desenvolvimento deste trabalho.

Às agencias financeiras CAPES, FAPESP, FAEPA e FUNDHERP pelo investimento realizado o qual viabilizou a execução deste trabalho. 
Ora et labora.

São Bento 


\section{RESUMO}

SILVA, A.B.A. Investigação dos efeitos da fenformina em neoplasias mieloproliferativas. 2020. 75 f. Dissertação (Mestrado em Ciências) - Faculdade de Medicina de Ribeirão Preto, Universidade de São Paulo, Ribeirão Preto, 2020.

Neoplasias mieloproliferativas (NMP) BCR-ABL1 negativas são caracterizadas por alterações moleculares que ocorrem a nível de célula-tronco e que desencadeiam proliferação excessiva das células da linhagem mieloide. As NMP BCR-ABL1 negativas clássicas são pela policitemia vera (PV), trombocitemia essencial (TE) e mielofibrose primária (MFP), que compartilham a ativação da via JAK/STAT, na maioria das vezes decorrente da presença da mutação JAK2 ${ }^{\mathrm{V} 617 \mathrm{~F}}$. As biguanidas, representada pela metformina e fenformina, são compostos extraídos de Galega officinalis que apresentam atividade hipoglicemiante para tratar pacientes com diabetes mellitus do tipo 2 (DM-2). Metformina inibe STAT3/5 e reduz o volume do baço em modelo murino e celular JAK2 ${ }^{\mathrm{V} 617 \mathrm{~F}}$. A fenformina é mais potente que a metformina. Testamos a hipótese que a fenformina poderia inibir o fenótipo de NMP em modelos JAK2 $2^{\mathrm{V} 617 \mathrm{~F}}$. O objetivo deste trabalho foi avaliar a capacidade antineoplásica da fenformina em modelos de NMP JAK2 ${ }^{\mathrm{V} 617 \mathrm{~F}}$. Linhagem celular SET-2, modelo murino de NMP JAK2 $2^{\mathrm{V} 617 \mathrm{~F}}$ e células primárias de pacientes com NMP foram utilizados. Viabilidade celular foi avaliada por ensaio de MTT e apoptose por Anexina-V7AAD. O modelo murino de NMP JAK2 ${ }^{\mathrm{V} 617 \mathrm{~F}}$ foi induzido pelo transplante de células provenientes da medula óssea total de camundongos JAK2 ${ }^{\mathrm{WT} / \mathrm{Fl}}-\mathrm{V}$ Vav/Cre CD45.2 em camundongos PepBoy C57BL/6 CD45.1, animais foram tratados com fenformina (40mg/kg/dia, intraperitoneal) ou veículo (PBS; 100 $\mu \mathrm{L} /$ dia, intraperitoneal) por 7 semanas e avaliados quanto aos parâmetros hematimétricos, tamanho e peso do baço, histologia do baço e da medula óssea, clonogenicidade e frequência de células-tronco. A avaliação da capacidade de autorrenovação da célula-tronco foi avaliada pelo transplante de células da medula óssea de animais $\mathrm{JAK}_{2}{ }^{\mathrm{WT} / \mathrm{Fl}}-$-Vav/Cre CD45.2 tratadas ex vivo com fenformina, metformina ou veículo e transplantadas em animais receptores Pepboy C57BL/6 CD45.1 irradiados com dose subletal. Células primárias de um paciente com MF foi tratada in vitro com fenformina ou veículo e submetida a ensaio de clonogenicidade. Para todas as análises estatísticas foi adotado nível de significância menor que 5\%, os testes Mann-Whitney, OneWay ANOVA ou Two-Way ANOVA foram realizados conforme apropriado. A fenformina 
5mM induziu apoptose celular em 49\%, 67\% e 75\% da população de células avaliadas após 24, 48 e 72 horas de exposição, respectivamente. Modelo murino JAK2 V617F tratados com fenformina $(n=7)$ ou veículo $(n=7)$ apresentaram resultados similares quanto às alterações hematológicas; tamanho e peso do baço. A arquitetura da medula óssea e do baço não diferiu entre os dois grupos. O ensaio de clonogenicidade demonstrou resultado similar entre os dois grupos. A análise da frequência das células-tronco hematopoéticas $(\mathrm{CTH})$ revelou aumento da população de progenitores mieloide (MP) (1.505 vs. 2.159, $p=0.0070)$, progenitores multipotentes ( 0.1265 vs. $0.2479, p=0.006)$ (MPP) e LSK (0.2608 vs. $0.3816, p=0.0023)$ na medula óssea do grupo de animais tratados com fenformina. Não houve diferença entre ambos os grupos quanto aos precursores eritroides no baço e na medula óssea. Transplante de medula óssea com células JAK2 $2^{\mathrm{V} 617 \mathrm{~F}}$ submetidas a tratamento ex vivo com fenformina (1mM, n=6), metformina (10mM, n=6) ou veículo (PBS, $n=6)$ resultou em enxertia e parâmetros hematimétricos semelhantes em todos os grupos, após de 16 semanas de acompanhamento $(p>0,05)$. A fenformina $(1 \mathrm{mM}$ ou $2 \mathrm{M})$ in vitro aboliu a formação de colônias em células primárias de paciente com MFP. Em conclusão, a fenformina in vitro apresentou efeito antineoplásico em modelos celulares JAK2 ${ }^{\mathrm{V} 617 \mathrm{~F}}$, mas não apresentou efeitos antineoplásicos em modelos in vivo e ex vivo de NMP JAK2 V617F.

Palavras-chave: Fenformina. JAK2 ${ }^{\mathrm{V} 617 \mathrm{~F}}$. Biguanidas. Policitemia vera. Modelo murino. 


\section{ABSTRACT}

SILVA, A.B.A. Investigation of the effects of phenformin in myeloproliferative neoplasm. 2020. 75 f. Dissertação (Mestrado em Ciências) - Faculdade de Medicina de Ribeirão Preto, Universidade de São Paulo, Ribeirão Preto, 2020.

BCR-ABL1 negative myeloproliferative neoplasms (MPN) are characterized by molecular changes that occur at the stem cell level and that trigger excessive proliferation of cells of the myeloid lineage. Classic MPN BCR-ABL1 negative are polycythemia vera (PV), essential thrombocythemia (ET) and primary myelofibrosis (PMF), which share the activation of the JAK/STAT pathway, most often due to the presence of the JAK2 $2^{\mathrm{V} 617 \mathrm{~F}}$ mutation. Biguanides, represented by metformin and phenformin, are compounds extracted from Galega officinalis that have hypoglycemic activity to treat patients with type 2 diabetes mellitus (DM-2). Metformin inhibits STAT3/5 and reduces the spleen volume in a murine and cellular JAK2 ${ }^{\mathrm{V} 617 \mathrm{~F}}$ model. Phenformin is more potent than metformin. We tested the hypothesis that phenformin could inhibit the MPN phenotype in JAK2 ${ }^{\mathrm{V} 617 \mathrm{~F}}$ models. The aim of this work was to evaluate the antineoplastic capacity of phenformin in MPN JAK2 $2^{\mathrm{V} 617 \mathrm{~F}}$ models. The SET-2 cell line, murine model of MPN JAK2 ${ }^{\mathrm{V} 617 \mathrm{~F}}$, and primary cells from PMF patient were used. Cell viability was assessed by MTT assay, and apoptosis by Anexina-V$7 \mathrm{AAD}$. The murine model of MPN JAK2 ${ }^{\mathrm{V} 617 \mathrm{~F}}$ was induced by transplanting $5 \times 10^{6}$ whole

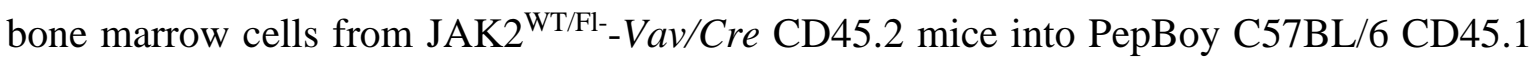
mice. Animals were treated with phenformin $(40 \mathrm{mg} / \mathrm{kg} / \mathrm{day}$, intraperitoneal) or control (PBS; $100 \mu \mathrm{L} /$ day, intraperitoneal) for 7 weeks and evaluated for hematimetric parameters, spleen size and weight, spleen and bone marrow histology, clonogenicity, and stem cells frequency. The evaluation of the stem cells self-renewal capacity was assessed by transplanting bone marrow cells from $\mathrm{JAK} 2^{\mathrm{WT} / \mathrm{Fl}}-$ Vav/Cre $\mathrm{CD} 45.2$ animals treated ex vivo with phenformin, metformin or control and transplanted into recipient Pepboy C57BL/6 CD45.1 subletally irradiated. Primary cells from PMF patient were treated in vitro with phenformin or control and subjected to a clonogenicity assay. For all statistical analyzes, a significance level of less than 5\% was adopted, the Mann-Whitney, One-Way ANOVA or Two-Way ANOVA tests were performed as appropriate. $5 \mathrm{mM}$ phenformin induced cell apoptosis in $49 \%, 67 \%$ and $75 \%$ of the cell population evaluated after 24,48 and 72 hours of exposure, respectively. Murine JAK $2^{\mathrm{V} 617 \mathrm{~F}}$ model treated with phenformin $(\mathrm{n}=7)$ or control $(n=7)$ showed no difference in hematological changes, spleen size and weight. The bone 
marrow and spleen architecture did not differ between the two groups. The clonogenicity assay demonstrated no difference in the number of colonies between the two groups. The analysis of the frequency of hematopoietic stem cells (HSC) revealed an increase in the population of myeloid progenitors (MP) (1,505 vs. 2,159, $p=0.0070)$, multipotent progenitors $(0.1265$ vs. $0.2479, p=0.006)(\mathrm{MPP})$ and $\operatorname{LSK}(0.2608$ vs. $0.3816, \mathrm{p}=0.0023)$ in the bone marrow of the group of animals treated with phenformin. There was no difference between both groups in terms of erythroid precursors in the spleen and bone marrow. Bone marrow transplantation with $\mathrm{JAK} 2^{\mathrm{V} 617 \mathrm{~F}}$ cells submitted to ex vivo treatment with phenformin $(1 \mathrm{mM}, \mathrm{n}=6)$, metformin $(10 \mathrm{mM}, \mathrm{n}=6)$ or vehicle (PBS, $\mathrm{n}=6)$ resulted in grafting and similar hematimetric parameters in all groups after 16 weeks of follow-up ( $>0.05)$. Phenformin ( $1 \mathrm{mM}$ or $2 \mathrm{Mm})$ in vitro abolished colony formation in PMF primary cells. In conclusion, phenformin in vitro showed antineoplastic effect in JAK2 ${ }^{\mathrm{V} 617 \mathrm{~F}}$ cell models, but did not show antineoplastic effects in vivo and ex vivo models of MPN JAK2 $2^{\mathrm{V} 617 \mathrm{~F}}$.

Keywords: Phenformin. JAK2 ${ }^{\mathrm{V} 617 \mathrm{~F}}$. Biguanides. Polycythemia vera. Murine model. 


\section{LISTA DE SIGLAS E ABREVIATURAS}

AF - Anemia de Fanconi

CALR - Calreticulina

CEP - Comitê de Ética em Pesquisa

CEUA - Comitê de Ética no Uso de Animais

CTC - Centro de terapia celular

CTH - Célula-tronco Hematopoética

CTL - Célula-tronco Leucêmica

CTPH - Célula-tronco progenitora hematopoética

DM-2 - Diabetes mellitus tipo 2

EDTA - Ácido etilenodiamino tetra-acético

EPO - Eritropoetina

EpoR - Receptor de Eritropoetina

EROs - Espécies Reativas do Oxigênio

FCFRP-USP - Faculdade de Ciências Farmacêuticas de Ribeirão Preto da Universidade de São Paulo

FDA- Food and Drug Administration

FSC - Foward Side Scatter

FMRP - Faculdade de Medicina de Ribeirão Preto

GM-CSF - Fator Estimulador de Formação de Colônia Macrofágica-Granulocítica

$\mathrm{Hb}-$ Hemoglobina

HCFMRP-USP - Hospital das Clínicas da Faculdade de Medicina de Ribeirão Preto

da Universidade de São Paulo

$\mathrm{Ht}$ - Hematócrito

IC50 - Concentração Inibitória

IFN- $\gamma$ - Interferon Gama

IGF1 - Fator de crescimento de insulina 1

IGF1R - Receptor do fator de crescimento de insulina 1

IL3 - Interleucina 3

IL5 - Interleucina-5

IL6 - Interleucina 6 
IP - Intraperitoneal

IR- $\beta$ - Receptor de Insulina- $\beta$

JAK - Janus quinase

JH1 - Tirosinoquinase C-terminal

JH2 - Janus Homology-2

LDH - Lactato desidrogenase

LEC - Leucemia Eosinofílica Crônica

LMA - Leucemia Mieloide Aguda

LMC - Leucemia Mieloide Crônica

LNC - Leucemia Neutrofílica Crônica

LT-HSC - Célula-tronco hematopoética de longo termo

MFP - Mielofibrose Primária

MF - Mielofibrose

MM - Mieloma Múltiplo

MO - Medula óssea

MPL - myeloproliferative leucemia vírus oncogene

MPP - Progenitor Multipotente

NMP - Neoplasias Mieloproliferativas

OXPHOS - Fosforilação oxidativa

PBS - Tampão fosfato-salino

PI3K - Fosfoinositídeo 3-quinase

PV - Policitemia Vera

SCF - Fator de célula-tronco

SFB - Soro Fetal Bovino

SFC - Soro Fetal de Cavalo

SFE - Soro Fetal Equino

SMD - Síndrome Mielodisplásica

$\mathrm{SP}$ - Sangue periférico

SSC - Side Scatter

STAT - Transdutoras de sinais e ativadoras de transcrição

ST-HSC - Célula-tronco hematopoética de curto termo

SUS - Sistema Único de Saúde

TE - Trombocitemia Essencial 
TMO - Transplante de Medula Óssea

TPO - Trombopoetina

v-MPL - Proto-oncogene homólogo ao oncogene do vírus da leucemia mieloproliferativa 


\section{LISTA DE FIGURAS}

Figura 1 - Camundongos Pepboy C57BL/6 CD45.1 foram letalmente irradiados com 7Gy de raios x. Camundongos $\mathrm{JAK}^{\mathrm{WT} / \mathrm{Fl}^{-}}-\mathrm{Vav} / \mathrm{Cre} \mathrm{CD} 45.2$ foram eutanasiados, fêmures, tíbia e coluna vertebral foram separados para obtenção da MO. $5 \times 10^{6}$ células totais da MO dos animais JAK2 ${ }^{\text {WT/Fl-}}-$ Vav/Cre CD45.2 foram injetadas via plexo retro-ocular dos camundongos Pepboy C57BL/6 CD45.1 para indução de NMP. Após 4 semanas do TMO, os animais foram submetidos a análise do quimerismo (CD45.2/CD45.1) e do hemograma para divisão em grupos que seriam tratados com fenformina $40 \mathrm{mg} / \mathrm{kg} / \mathrm{dia}$ via intraperitoneal (IP) e grupos que receberiam apenas veículo (PBS; $100 \mu \mathrm{L} /$ dia via IP).

Figura 2. Demonstração do método utilizado por citometria de fluxo para identificação das células que foram marcadas com os anticorpos CD45.1 e CD45.2. O primeiro quadrante, na esquerda para a direita, observa-se a seleção de células viáveis provenientes do SP dos camundongos submetidos ao transplante de medula óssea. A seleção é feita pela complexidade (SSC) e pelo tamanho das células (FSC). No segundo quadrante encontra-se a separação de agregados celulares que possam ter sido confundidos pelo citômetro como uma única célula, então a seleção é feita pela área celular (FSC-A) e pela altura (FSC-H). No terceiro quadrante, na parte inferior direita estão as células que foram positivamente marcadas para o anticorpo CD45.2. As marcações CD45.1 e CD45.2 identificam as células dos animais receptores Pep/Boy C57BL/6 CD45.1 e dos animais doadores JAK2 ${ }^{\mathrm{WT} / \mathrm{Fl}-}-$ Vav/Cre CD45.2, respectivamente.

Figura 3 -Animais Pepboy C57BL/6 CD45.1 foram irradiados subletalmente com raios x. A medula óssea (MO) dos animais JAK2 $2^{\mathrm{WT} / \mathrm{Fl}-}-$ Vav/Cre CD45.2 foi obtida por crushing de fêmures, tíbias e coluna vertebral dos animais. As células da MO foram cultivadas durante $18 \mathrm{~h}$ na presença ou ausência de fenformina, metformina ou veículo (PBS). Após o período de cultivo, as células foram transplantadas nos camundongos Pepboy C57BL/6 previamente irradiado subletalmente. Os animais foram acompanhados quanto ao hemograma e quimerismo a cada 15 dias durante o primeiro mês e posteriormente a cada 30 dias até o $4^{\circ}$ mês.

Figura 4. Curva dose-resposta indicam o efeito exercido pela fenformina em relação à concentração. As doses utilizadas estão representadas no eixo X e os efeitos percentuais observados de redução de viabilidade encontram-se representados no eito Y. A curva representa a média das réplicas do efeito da fenformina nos diferentes tempos de exposição e às diferentes concentrações.

Figura 5 - Fenformina aumenta o percentual de células em apoptose de forma dose e tempodependente. Os gráficos apresentam as médias com desvio padrão das células SET-2 tratadas com fenformina em diferentes concentrações por 24,48 ou $72 \mathrm{~h}$. A apoptose foi avaliada por citometria de fluxo por meio da marcação das células com Anexina -V e 7-AAD. Os resultados apresentados nos gráficos são referentes a quatro experimentos independentes. Os valores de $p$ são apresentados como *p<0.05; ** $p<0.01$; *** $p<0.001$ em relação ao controle (Ø). Teste Two-way ANOVA.

Figura 6 - Gráficos de pontos representativos para análise de apoptose em células SET-2 tratadas com veículo ou fenformina. Células SET-2 foram tratadas com veículo (PBS) ou diferentes doses 
de fenformina, durante 24, 48 ou 72 horas. O quadrante inferior direito indica as células Anexina-V (APC) positivas, o quadrante superior esquerdo as células positivas para 7-AAD e o quadrante superior direito representa as células Anexina-V positivas e 7-AAD positivas, foram consideradas as células Anexina-V e 7AAD.

Figura 7 - Quimerismo dos camundongos Pepboy C57BL/6 CD45.1 submetidos ao TMO com células provenientes de camundongos JAK2 ${ }^{\mathrm{WT} / \mathrm{FI}^{-}}-$Vav/Cre CD45.2. Após 4 semanas do TMO, o quimerismo dos animais foi realizado em sangue periférico e a marcação foi realizada com os anticorpos PECD45.1 e FITC-CD45.2. O quadrante inferior direito representa as células do camundongo doador FITCCD45.2. A aquisição foi feita no citômetro FACSCalibur (BD, Biosciences), e a análise no Programa FlowJo (TreestarINC).

Figura 8 - Fenformina in vivo não modulou parâmetros hematimétricos em modelo murino JAK2 ${ }^{\mathrm{V} 617 \mathrm{~F}}$. Parâmetros hematimétricos foram avaliados em modelo murino JAK2 ${ }^{\mathrm{V} 617 \mathrm{~F}}$ tratados in vivo com fenformina 40mg/kg/dia $(\mathrm{n}=7)$ ou veículo (PBS; $100 \mu \mathrm{L} / \mathrm{dia})(\mathrm{n}=7)$ intraperitoneal durante 7 semanas. No eito Y estão os valores das unidades dos parâmetros hematimétricos avaliados, os valores de referência preconizados pelo The Jackson Laboratory são exibidos pelos pontos tracejados que partem da esquerda para direita no eixo Y. No eixo X estão os dias decorridos do tratamento com fenformina ou veículo. Não houve modulação nos parâmetros hematimétricos avaliados. Teste de Mann-Whitney, $p>0.05$.

Figura 9 - Tratamento com fenformina não modula a esplenomegalia em modelo murino JAK2 $^{\mathrm{V617F}}$. Modelo murino JAK2 $2^{\mathrm{V} 617 \mathrm{~F}}$ tratado in vivo com fenformina 40mg/kg/dia ou veículo (PBS, 100 $\mu \mathrm{L} /$ dia) intraperitoneal durante 7 semanas foram submetidos à eutanásia e avaliação do peso e tamanho do baço. Na figura à esquerda, o eixo Y indica o peso do baço dos animais em gramas, a linha horizontal representa a mediana com intervalo interquartil do peso do baço no grupo tratado com veículo $(n=7)$ ou fenformina $(n=7)$; Teste de Mann-Whitney, $p>0,05$. Valores de referência preconizados pelo The Jackson Laboratory são exibidos pelos pontos tracejados que partem do eixo Y. A figura à direita é a imagem do baço de animais tratados com veículo (alinhados na parte superior) ou fenformina (alinhados na parte inferior). O tratamento com fenformina, no regime utilizado, não foi capaz de modular a esplenomegalia apresentada pelos animais Pepboy C57BL/6 CD45.1 transplantados com células provenientes de camundongos JAK2 ${ }^{\text {WT/FI--Vav/Cre }}$ CD45.2.

Figura 10 - A clonogenicidade das células da medula óssea dos animais tratados com fenformina e veículo foi semelhante. Os gráficos representam as colônias viáveis que foram cultivadas por 10 dias com células provenientes da MO de camundongos submetidos ao tratamento diário com fenformina 40mg/kg/dia IP ou veículo por 7 semanas. O número de colônias (eixo Y) e o tipo de colônia (eixo X) observada com base em sua morfologia estão ilustrados (painel esquerdo). O percentual de predominância de um determinado tipo morfológico de colônia em ambos os grupos experimentais (controle e tratados) são ilustrados (painel direito). As unidades formadoras de colônias são classificadas em: granulocítica (CFU-G), macrofágicas (CFU-M), granulocítica-macrofágica (CFU-GM) e unidades formadoras de colônias eritroides (CFU-E). Não foi observada a formação de nenhuma colônia eritroide. Teste Two-way ANOVA, $p>0.05$. 
Figura 11 - Não houve diferença com relação a contagem de megacariócitos na histologia do baço ou da medula óssea dos animais tratados com fenformina ou veículo. O número de megacariócitos contados em 3 campos (eixo Y) na avaliação histológica dos grupos experimentais controle e fenformina são indicados. Não houve diferença no número de megacariócitos entre o grupo controle e grupo tratado. Teste de Mann-Whitney, $p>0.05$.

Figura 12 - Fenformina aumentou a frequência da população LSK, MPP e MP na medula óssea dos animais. A identificação da frequência de células-tronco hematopoéticas (CTH) foi realizada por citometria de fluxo por meio da marcação com anticorpos Sca-1, CD117 (c-kit), CD48 e CD150. O percentual da população de células avaliadas na medula óssea dos animais submetidos ao tratamento está indicado no eixo Y, os grupos experimentais que receberam tratamento diário com fenformina 40mg/kg/dia IP ou veículo (PBS, $100 \mu \mathrm{L}$ ) estão indicados no eixo X. As linhas horizontais representam a média com desvio padrão de cada grupo avaliado. Os valores de $p$ são apresentados como ** $p<0.01 ; * * * p<0.001$. Teste de Mann-Whitney.

Figura 13 - Não houve diferença no percentual de precursores eritroides no baço ou na medula óssea em ambos os grupos, fenformina $40 \mathrm{mg} / \mathrm{kg} / \mathrm{dia}$ IP ou veículo (PBS, 100 $\mu \mathrm{L}$ ). Os precursores eritroides foram avaliados por citometria de fluxo pela marcação das células provenientes do baço ou da medula óssea (MO) com os anticorpos CD71 e Ter119. Cada gráfico apresenta no eixo Y o percentual de cada população de precursores eritroides no baço ou na MO dos camundongos. O eixo X representa os dados referentes aos grupos controle e tradados. Não houve diferença na população de precursores eritroides em ambos os grupos avaliados, tanto no baço quanto na MO provenientes dos animais submetidos ao transplante de medula óssea e tratados ou não diariamente com fenformina 40mg/kg/dia IP durante 7 semanas. Os gráficos apresentam os valores das médias com desvio-padrão. Teste de Mann-Whitney, $p>0,05$.

Figura 14 - Após 16 semanas de seguimento, o quimerismo e os parâmetros hematimétricos não diferiram entre os grupos de animais transplantados com células JAK2 ${ }^{\text {WTLL- } V a v / C r e ~ C D 45.2 ~ e ~ t r a t a d a s ~}$ ex vivo com fenformina, metformina ou veículo. Após o transplante de células tratadas ex vivo com fenformina, metformina ou veículo em animais receptores Pepboy C57BL/6 CD45.1, os animais receptores foram acompanhados durante 16 semanas e avaliados quanto ao quimerismo e parâmetros hematimétricos. No eixo Y de cada gráfico encontra-se o quimerismo e os parâmetro hematimétricos avaliados e no eito X o tempo de acompanhamento dos animais. O quimerismo foi avaliado por citometria de fluxo pela marcação das células do sangue periférico dos animais com os anticorpos PE-CD45.1 e FITC-CD45.2. Os gráficos apresentam os valores das médias com desvio-padrão e os valores de $p$ são apresentados como $* p<0.05 ; * * p<0.01$. Teste One-Way ANOVA.

Figura 15 - A fenformina inibe a formação de colônias em células primárias JAK ${ }^{\mathrm{V} 617 \mathrm{~F}}$. As células provenientes de paciente com JAK2 ${ }^{\mathrm{V} 617 \mathrm{~F}}$ foram cultivadas por 14 dias na ausência ou presença de fenformina em diferentes concentrações ( $1 \mathrm{~mm}$ ou $2 \mathrm{mM}$ ) em estufa com $\mathrm{CO}_{2}$. O gráfico representa no eixo $\mathrm{Y}$ o número de colônias identificadas no experimento e no eixo X a concentração de fenformina utilizada. A barra representa a quantidade de cada tipo morfológico de colônia identificada. Fenformina a partir de $1 \mathrm{mM}$ aboliu a clonogenicidade das células. 


\section{LISTA DE TABELAS}

Tabela 1. Parâmetros hematimétricos normais para camundongos Pep/boy C57BL/6-CD45.1.

Tabela 2. Imunofenótipo de células tronco e progenitoras hematopoéticas avaliados.

Tabela - 3. Parâmetros hematimétricos dos camundongos submetidos ao TMO com células provenientes de animais JAK2 ${ }^{\mathrm{WT} / \mathrm{Fl}}-\mathrm{Vav} / \mathrm{Cre}$ CD45.2 4 semanas após o procedimento e randomização em grupos tratados e controle.

Tabela 4 - Avaliação do valor médio dos parâmetros clínicos e laboratoriais de camundongos Pepboy C57BL/6 CD45.1 receptores de células hematopoéticas de camundongos JAK2 ${ }^{\mathrm{WT} / F 1}$-Vav/Cre CD45.2 na randomização entre grupos controles e tratados.

Tabela 5 - Avaliação histopatológica do baço e da MO dos animais Pepboy C57BL/6 transplantados com células de animais JAK2 ${ }^{\mathrm{WT} / F L}-$-Vav/Cre CD45.2 e tratados com fenformina.

Tabela 6. Peso médio dos animais no dia do TMO para separação em grupos que receberiam as células JAK2WT ${ }^{/ \mathrm{FL}-\text {-Vav/Cre } C D 45.2}$ tratadas ex vivo. 


\section{SUMÁRIO}

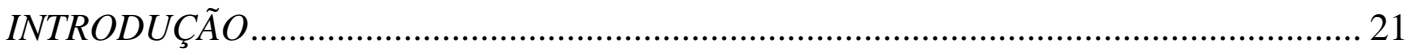

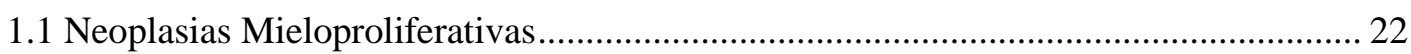

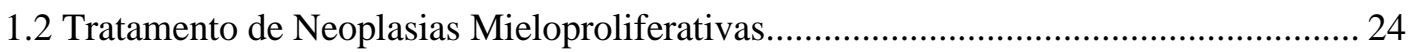

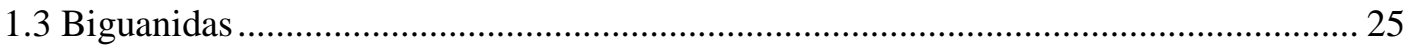

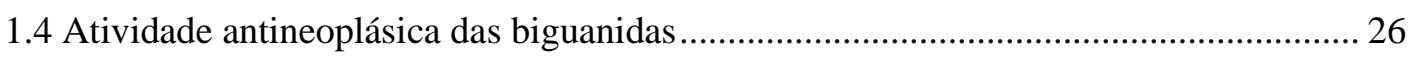

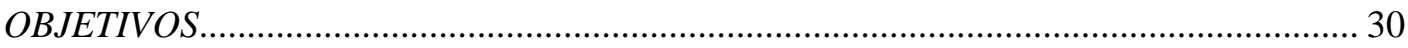

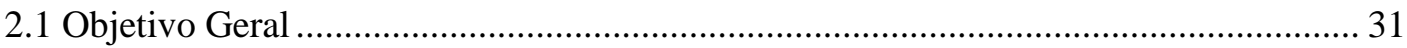

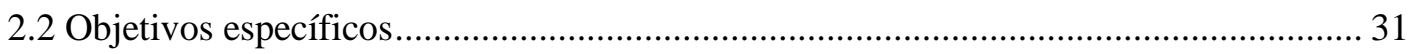

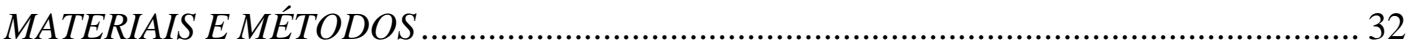

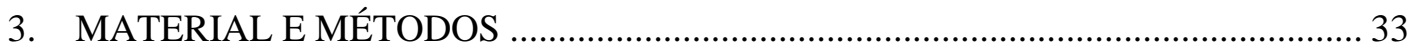

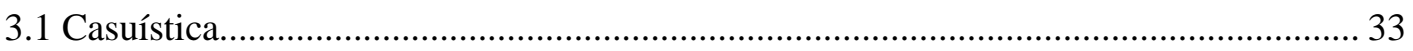

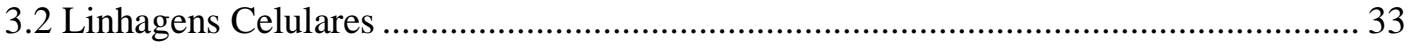

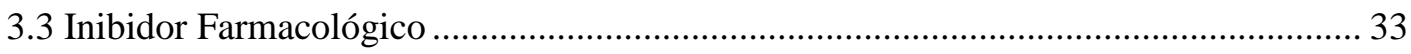

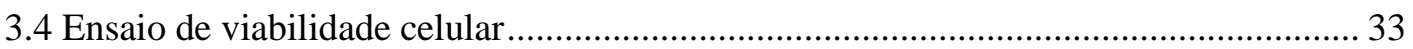

3.5 Análise da apoptose celular por Anexina-V e 7-AAD .................................................. 34

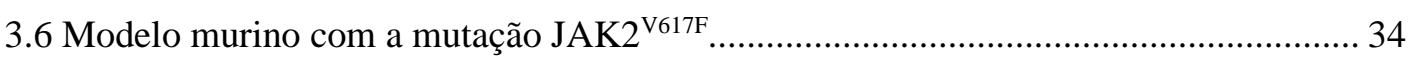

3.7 Tratamento in vivo de fenformina em modelo murino de NMP JAK2 ${ }^{\mathrm{WT} / \mathrm{Fl}-}-$ Vav/Cre $\ldots . .35$

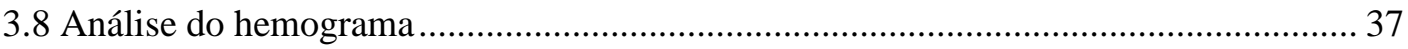

3.9 Quantificação das células-tronco hematopoéticas e precursores hematopoéticos.......... 38

3.10 Avaliação histológica do baço e medula óssea............................................................ 39

3.11 Avaliação da capacidade clonogênica de células progenitoras hematopoéticas .......... 39

3.12 Avaliação do efeito do tratamento ex vivo da fenformina na capacidade de autorrenovação de células-tronco e progenitoras hematopoéticas em modelo murino NMP JAK2 ${ }^{\text {WT/Fl- }}$ -Vav/Cre.

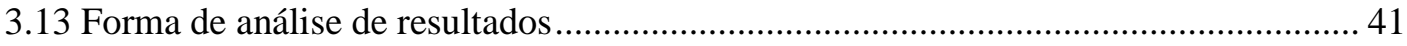

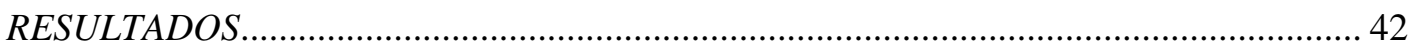


4.1 Fenformina reduz a viabilidade e aumenta apoptose em células JAK2 ${ }^{\mathrm{V} 617 \mathrm{~F}}$

4.2 Tratamento com fenformina in vivo em modelo murino de NMP induzida por JAK2 $2^{\text {WT/FI- }}$ -Vav/Cre CD45.2

4.3 O tratamento ex vivo com fenformina não modula a capacidade de autorrenovação e diferenciação de células-tronco e progenitoras hematopoéticas em modelo murino de NMP induzida por JAK2 $2^{\mathrm{V} 617 \mathrm{~F}}$

4.4 Fenformina inibe a capacidade de formação de colônia de células primárias de paciente JAK2 $2^{\mathrm{V} 617 \mathrm{~F}}$ 57

CONCLUSÕES 63

6. Conclusões 64

REFERÊNCIAS 65

ANEXOS 70 
INTRODUÇÃO 


\section{Introdução}

\subsection{Neoplasias Mieloproliferativas}

Neoplasias mieloproliferativas (NMP) constituem um grupo de entidades hematológicas clonais que compartilham características clínicas e moleculares em que alterações genéticas na célula-tronco hematopoética garantem vantagem proliferativa a essas células ${ }^{1}$. As NMP são caracterizadas pela hiperplasia de células maduras na medula óssea (MO) e no sangue periférico (SP) ${ }^{2}$. A mortalidade e morbidade das NMP são frequentemente decorrentes de episódios trombo-hemorrágicos e progressão para mielofibrose (MF) ou leucemia mieloide aguda $(\mathrm{LMA})^{3}$. Fazem parte das neoplasias mieloproliferativas a leucemia mieloide crônica (LMC), leucemia neutrofílica crônica (LNC), leucemia eosinofílica crônica (LEC), policitemia vera (PV), mielofibrose primária (MFP), trombocitemia essencial (TE) e NMP não classificável. As NMP são categorizadas de acordo com mutações e/ou rearranjos de genes codificadores de tirosinoquinases. LMC é caracterizada pela presença da translocação cromossômica t $(9 ; 22)$ (q34; q11) e rearranjo BCR-ABL1. As principais entidades de NMP BCR-ABL1 negativas são PV, MFP e TE, caracterizadas por ativação da via JAK2/STAT na maioria dos casos decorrente da mutação somática JAK2 $2^{\mathrm{V} 617 \mathrm{~F} 4,5}$.

A PV caracteriza-se pela hipercelularidade da MO associada a panmielose ${ }^{4,6,7}$, inicialmente pode apresentar-se clinicamente como eritrocitose isolada, leucocitose, trombocitose ou a combinação destes achados acompanhada de hematopoese extramedular ou fibrose na $\mathrm{MO}^{8}$. Normalmente duas fases de PV são reconhecidas: uma fase policitêmica que é associada ao aumento do número de eritrócitos, hemoglobina e do hematócrito; e a mielofibrose pós-PV, com citopenias, fibrose da MO, hematopoese extramedular e esplenomegalia. Os sintomas apresentados pelos pacientes consistem em hipertensão ou alterações vasculares causadas pelo aumento de eritrócitos; trombose é a primeira manifestação de PV em aproximadamente $20 \%$ dos $\operatorname{casos}^{1}$. Alguns pacientes podem apresentar fadiga, sudorese noturna e prurido ${ }^{9}$. A história natural da doença tem uma baixa incidencia de evolução para LMA ${ }^{1}$. TE distingue-se pela contagem do número de plaquetas superior a $450 \times 10^{9} / \mathrm{L}^{1}$ e alto risco de eventos trombóticos e hemorrágicos ${ }^{10}$. O diagnóstico de TE é realizado por exclusão de outras causas que possam desencadear trombocitose e pela presença de hiperplasia de megacariócitos hipernucleados na $\mathrm{MO}^{1,11}$. A MFP pode ser identificada em duas fases, a fase pré-fibrótica, caracterizada pela proliferação granulocítica e megacariocítica com atipias de megacariócitos, 
com fibrose reticular menor que 1, e em fase fibrótica, caracterizada por fibrose reticulínica ou colágena grau II ou III ${ }^{4,6,7}$.

São reconhecidas três principais mutações que participam da fisiopatologia da PV, MFP e TE. As mutações conduzem a ativação constitutiva da cascata de sinalização de tirosinoquinases que permitem a célula proliferação de maneira independente ${ }^{6,12-14}$, as mutações ocorrem nas proteínas JAK2 (Janus Kinase 2, localizada no cromossomo 9p24), CALR (calreticulina, localizada no cromossomo 19p13.2) e MPL (myeloproliferative leucemia vírus oncogene, localizada no cromossomo $1 \mathrm{p} 34)^{15}$. A mutação na JAK2 é encontrada em 95\% dos pacientes com diagnostico de PV e em 20-40\% dos pacientes com TE ou MFP ${ }^{6,12,13,16}$. A mutação em CALR é encontrada em aproximadamente 20-25\% dos pacientes com MFP e TE; e a presença da mutação em MPL é encontrada em até 7\% dos pacientes com MFP e TE ${ }^{17,18}$. Aproximadamente 10-25\% dos pacientes com MFP e TE são triplo-negativos, ou seja, não possuem nenhuma das três mutações ${ }^{19-21}$.

A família de genes Janus quinase (JAK) é constituída de quatro membros principais: $J A K 1, J A K 2, J A K 3$ e TYK2 22,23. JAK2 é um importante membro da família Janus quinase, os quais compartilham alta homologia estrutural, encontra-se amplamente distribuído no citoplasma de células somáticas e está envolvido na transdução de sinais por meio de vias dos sistemas hematopoiético e imune ${ }^{24}$. A ativação de JAK2 é mediada por sua associação aos receptores de eritropoetina (EpoR), trombopoetina (MPL), fator estimulador de formação de colônia macrofágica-granulocítica (GM-CSF), interleucina (IL) 3 e IL5, e participa da regulação da expressão de genes envolvidos na sobrevivência e proliferação celular ${ }^{15,22}$.

Os receptores JAK possuem quatro domínios estruturais, um domínio FERM Nterminal, um domínio SH2, um domínio pseudoquinase (JH2 [Janus homology-2]) e um domínio de tirosinoquinase C-terminal (JH1). O domínio JH1 é responsável majoritariamente pela fosforilação de JAK, JH1 cataliza o processo de transfosforilação de dois resíduos de tirosinoquinase de JAK, os quais são responsáveis pela sua estabilização, e o domínio JH2 atua como um regulador negativo da fosforilação de $\mathrm{JH} 1{ }^{23}$. Uma vez ativada, JAK fosforila os resíduos de tirosina no domínio citoplasmático do receptor e em si, promovendo ativação de proteínas de sinalização, tais como transdutoras de sinais e ativadoras de transcrição (STAT) e outras vias de sinalização como fosfoinositídeo 3-quinase (PI3K) e MAPK ${ }^{22}$. STATs são um conjunto de proteínas que se tornam substratos e são fosforiladas por JAK, formando dímeros e se deslocando para o núcleo onde modificam a expressão gênica ${ }^{25}$. 
A mutação JAK2 ${ }^{\mathrm{V} 617 \mathrm{~F}}$ é uma mutação de ponto e consiste na troca de uma guanina por uma timina na posição 1849, a troca resulta na substituição de valina por fenilalanina na posição 617 do éxon 14 (V617F) 6,12,13,16. Mutações em outros éxons de JAK2 também foram descritas em pacientes negativos para JAK2 ${ }^{\mathrm{V} 617 \mathrm{~F}}$, como a mutação K539L no éxon 12, em que os pacientes apresentam alta eritrocitose, baixos níveis séricos de eritropoetina e alta taxa de fosforilação de JAK2, quando comparadas com JAK2 ${ }^{\mathrm{V} 617 \mathrm{~F}}$ 26,27. A hipótese acerca do papel exercido pelos domínios a partir da mutação JAK2 $2^{\mathrm{V} 617 \mathrm{~F}}$ é que a função autoinibitória de JH2 sobre JH1 está comprometida e assim JH2 promove a dimerização de JAK2 na ausência de citocinas, facilitando a transfosforilação de $\mathrm{JH}^{23}$, que resulta na ativação constante de JAK2 e proliferação excessiva de células mieloides. Para pacientes com mutação em JAK2, a taxa de sobrevida é estimada em 19 anos para TE, 14 anos para PV e 5 anos para MFP ${ }^{28}$.

Calreticulina (CALR) é uma proteína que desempenha diversas funções biológicas, podendo ser encontrada no meio intracelular e extracelular, seu papel no retículo endoplasmático é assegurar o envelopamento de novas glicoproteínas e regular a homeostase do cálcio $^{29,30}$. Mutações em CALR são classificadas como Tipo 1 (deleção) e Tipo 2 (inserção) e ocorrem na região C-terminal da proteína ${ }^{30-32}$. A mutação confere carga elétrica positiva à região C terminal da CALR e ganho de função; CALR se liga a MPL no retículo endoplasmático, transloca-se ligada ao MPL para a membrana citoplasmática e ativa MPL independente do ligante, com consequente ativação da via JAK2/STAT ${ }^{21,33,34}$.

O receptor de trombopoetina (MPL) é o proto-oncogene homólogo ao oncogene do vírus da leucemia mieloproliferativa (v-MPL) ${ }^{7,35,36}$. Mutações no éxon 10 de MPL ativam a via de sinalização JAK/STAT de forma constitutiva ${ }^{34}$, com consequente ativação de STAT3/5, MAPK e PI3K/AKT. As células hematopoéticas que expressam a proteína MPL com a mutação W515L se tornam hipersensíveis ao estímulo com $\mathrm{TPO}^{37-39}$.

\subsection{Tratamento de Neoplasias Mieloproliferativas}

O principal objetivo do tratamento de NMP é reduzir os sintomas clínicos, os riscos de eventos trombóticos e de evolução para mielofibrose, em casos de PV e TE, ou manejo para que se evite a progressão para LMA. Em PV, os pacientes são submetidos a procedimentos de flebotomia a fim de manter os níveis de hematócrito inferiores a 45\%; a terapia citorredutora é recomendada para pacientes com alto risco ( idade superior a 60 anos ou história prévia de trombose arterial ou venosa) ${ }^{9,18,40}$. O tratamento para TE é feito com administração de aspirina 
a fim de se prevenir as complicações trombóticas ${ }^{11,40}$. O tratamento para MFP depende da apresentação clínica do paciente e consiste basicamente de terapia citorredutora para os casos pré-fibróticos e terapia de suporte para melhora da anemia para fase fibrótica. O ruxolitinibe, inibidor seletivo de JAK1/2, foi aprovado para uso na mielofibrose em 2011 pelo Food and Drug Administration (FDA) dos Estados Unidos, porém não está disponível no Sistema Único de Saúde (SUS) no Brasil ${ }^{41,42}$. O tratamento com células-tronco hematopoéticas (CTH) é o único tratamento com potencial curativo, porém limita-se a pacientes elegíveis ${ }^{43}$.

O ruxolutinibe reduz os sintomas sistêmicos e a esplenomegalia, mas não altera a evolução natural da doença e não elimina os clones mutados ${ }^{7,14,23}$. Em modelo murino JAK2 ${ }^{\mathrm{V} 617 \mathrm{~F}}$ foi demonstrado que o ruxolitinibe não afeta as CTH mutadas e não induz a remissão da doença ${ }^{21}$. A ausência de tratamento que evite a progressão de NMP e induz a remissão clínica e molecular lança luz sobre a necessidade do desenvolvimento de novas terapias ou terapias complementares para NMP BCR-ABL1 negativas.

\subsection{Biguanidas}

Biguanidas são compostos ativos extraídos de Galega officinalis que apresentam efeito terapêutico para o tratamento de diabetes mellitus tipo 2 (DM-2). Os compostos derivados de de Galega officinalis reduzem a hiperglicemia e a hiperinsulinemia associada ao diabetes. As biguanidas reduzem a resistência à insulina, por meio da ativação do receptor de insulina, aspecto chave da fisiopatologia do DM- $2^{44}$.

A metformina é o representante das biguanidas mais disponível atualmente, sendo um agente hipoglicemiante bastante utilizado no tratamento do DM-2. A metformina e a fenformina foram introduzidas na terapêutica em 1957 e a buformina em 1958, a buformina teve uso limitado, enquanto a metformina e a fenformina foram amplamente comercializadas. A fenformina foi retirada do mercado em muitos países durante a década de 1970 devido à associação de seu uso com a manifestação clínica de acidose láctica. A metformina tem sido amplamente prescrita na Europa e no Canadá, e disponível nos EUA desde $1995^{45}$, e está associada ao risco real, mas substancialmente menor de acidose lática ${ }^{46,47}$. Supõe-se que tal efeito colateral de acidose láctica exercido pelas biguanidas seja reflexo da ativação acelerada da via glicolítica, a qual requer aumento de glicose e, consequentemente, aumenta a produção de lactato ${ }^{48}$. A metformina é amplamente utilizada no Brasil e está disponível no SUS ${ }^{49}$. 
As biguanidas atuam na mitocôndria e possuem como alvo principal o complexo mitocondrial da cadeia de transporte de elétrons I, o qual foi o primeiro sítio de ação identificado como alvo inibido ${ }^{44}$. O complexo mitocondrial I catalisa a oxidação do NADH, que é um importante passo para a geração de ânions superóxidos $\left(\mathrm{O}_{2-}\right)$, a inibição do complexo I é conhecida por aumentar a produção de $\mathrm{O}_{2}$, essa ação na mitocôndria resulta na aceleração compensatória de glicólise para compensar a produção reduzida de ATP via fosforilação oxidativa (OXPHOS). O aumento da razão de AMP para ATP resulta na ativação de AMPK, o qual acredita-se ser responsável pela atividade antitumoral ${ }^{44,48}$. Estudos iniciais mostram que AMPK encontra-se menos ativado em tecidos com proliferação neoplásica ${ }^{50}$.

Acredita-se que acidose lática causada pelas biguanidas deve-se a inibição do complexo I mitoncondrial. Por serem catiônicas, a metformina e fenformina acumulam-se na matriz mitocondrial, possivelmente devido a diferença eletrostática, e inibem diretamente o complexo $\mathrm{I}^{51}$. A fenformina também inibe os complexos I, II e IV de maneira dose-dependente ${ }^{52}$.

O uso de metformina, com efeito dose-dependente, é relacionado ao risco reduzido de câncer em pacientes com DM-2 ${ }^{53}$. O uso da metformina é associado com a prevenção de pólipos e adenomas hiperplásicos em pacientes não diabéticos e na melhora da taxa de sobrevida em pacientes com câncer colorretal e diabetes ${ }^{54,55}$.

\subsection{Atividade antineoplásica das biguanidas}

Tendo em vista a necessidade de múltiplos alvos terapêuticos para o tratamento das neoplasias hematológicas, as biguanidas destacam-se por seu potencial antineoplásico em diversos estudos pré-clínicos. Ambas as biguanidas são usadas como ativadores de AMPK e os efeitos celulares podem ser mediados por esta ação ${ }^{56}$. A fenformina atua inibindo a respiração mitocondrial de maneira dose-dependente, já tendo sido reportado na literatura que seu potencial de eficiência pode ser 10 vezes maior que o da metformina. In vitro, a fenformina diminui a sensibilidade do poro mitocondrial ativado por $\mathrm{Ca}^{2+}$ e reduz a taxa e a extensão do aumento de volume da matriz mitocondrial ${ }^{52}$.

O uso combinado de fenformina com um inibidor de BRAF (BRAFi) em um modelo experimental de melanoma $\mathrm{BRAF}^{\mathrm{V} 600 \mathrm{E}}$ mostrou uma vantagem terapêutica contra BRAF mutante em comparação ao uso de seu inibidor sozinho, tanto in vitro quanto in vivo. A fenformina é mais potente que a metformina na supressão de crescimento tumoral e os achados 
pré-clínicos indicam que a combinação de fenformina com BRAFi oferece uma alternativa terapêutica vantajosa a ser explorada ${ }^{57}$.

Em linhagens celulares de câncer de mama e próstata, fenformina foi capaz de induzir apoptose, impedir a progressão do ciclo celular e metástase de maneira dose-dependente ${ }^{58,59}$. Camundongos transgênicos MMTV/ErbB2 inoculados com células 78617, derivadas de tumor de mama de camundongos MMTV-ErbB2, foram tratados com fenformina e o tratamento inibiu o crescimento e reduziu a densidade tumoral. Em células SKBR3 e 78618, a fenformina inibiu a via de sinalização mediada por ErbB2 de maneira dose-dependente a partir da redução da fosforilação e ativação de ErbB2, AKT, mTOR e ERK e o tratamento das células que hiperexpressam ErbB2 demonstrou que a droga induziu a fosforilação de AMPK ${ }^{60}$.

$\mathrm{Na}$ avaliação de CTH observou-se que o tratamento com metformina reduz significantemente a produção de espécies reativas do oxigênio (EROs) pelas células de camundongos submetidos a irradiação total, indicando que a metformina pode inibir o estresse oxidativo induzido pela radiação. Após o tratamento com a metformina, os camundongos irradiados mostraram recuperação considerável e aumento da capacidade clonogênica das CTH, sem induzir citotoxicidade ${ }^{61}$. Em modelo de transplante competitivo para avaliação da quiescência das CTH induzida pelo processo de irradiação, camundongos foram tratados com metformina e posteriormente irradiados para transplante com células provenientes de animais sadios, o tratamento com metformina aumentou a frequência de células do doador, sugerindo influência da droga em preservar a capacidade funcional das CTH e melhorar a qualidade do enxerto ${ }^{61}$.

Em modelo murino de anemia de Fanconi (AF), a metformina auxiliou na hematopoese e retardou a formação de tumores sólidos. A administração crônica de metformina aumentou significantemente a frequência e a capacidade da CTH em camundongos adultos com $\mathrm{AF}^{62}$.

Em LMA, a metformina apresentou atividade antineoplásica in vitro, reduziu a proliferação, o crescimento de progenitores hematopoéticos e induziu à apoptose. Houve também aumento da sobrevida livre de tumor em camundongos imunocomprometidos sem efeitos citotóxicos sistêmicos aparentes ${ }^{63}$. Em linhagem celular humana Dami, modelo de LMA megacariocítica, a metformina reduziu a taxa de proliferação e aumentou a apoptose de maneira dose e tempo-dependente e inibiu as vias mediadas por $\mathrm{AKT}^{64}$.

Em mieloma múltiplo (MM), o tratamento com fenformina em células RPMI8226 e U266 reduziu a viabilidade celular e teve efeito sinérgico ao tratamento com bortezomibe. Quando comparadas as doses de fenformina e metformina usadas no estudo para se obter 
redução da viabilidade celular em ambas as linhagens, com 200uM de fenformina reduziu-se a viabilidade para menos de $40 \%$, enquanto que para obter o mesmo percentual de redução utilizou-se $4 \mathrm{mM}$ de metformina ${ }^{65}$.

O fator de crescimento semelhante à insulina I (IGF1) é reconhecido por promover o crescimento celular ${ }^{66}$. Nas células SKBR3 e 78618, a fenformina reduziu a expressão, fosforilação e ativação do receptor de IGF1 (IGFR1), inibiu IGF1 de maneira significativa, reduzindo também a ativação induzida por IGF1 em ErbB2, AKT, ERK e mTOR ${ }^{60}$. O prétratamento com fenformina em carcinoma hepatocelular sensibilizou as células para posterior tratamento com inibidores de mTOR, sugerindo ação da fenformina nesta via ${ }^{67}$. Nosso grupo demonstrou que a inibição de IGF1R-IRS1/2 apresentou efeitos antineoplásicos significativos em células JAK2 $2^{\mathrm{V} 617 \mathrm{~F}} 68$ e que a inibição de IRS2 potencializa o efeito antiproliferativo e próapoptótico do ruxolitinibe ${ }^{69}$.

A fenformina é capaz de inibir o consumo de oxigênio em aproximadamente $40 \% \mathrm{em}$ células de linhagem leucêmica OCI-AML3 na concentração de 50uM/L e aumentou a produção de EROs e teve efeito sinérgico quando combinada com ABT-737, um inibidor de BCL2. Em células primárias de LMA, apenas a fenformina, e não a metformina, sozinha ou em combinação com ABT-737, sensibilizou 3 de 5 amostras testadas de células leucêmicas, indicando que a droga pode potencializar o efeito do inibidor de BCL2 em células primárias ${ }^{70}$.

Estudos conduzidos para avaliar células-tronco leucêmicas (CTL) de LMC revelaram que o efeito da fenformina nessas células está relacionado a atividade inibitória exercida no complexo I da mitocôndria. Ao ser realizada a respirometria, observou-se que após 20 minutos de exposição ocorre redução significativa do consumo de oxigênio e que o uso combinado da fenformina com o imatinibe potencializa a inibição da capacidade clonogênica de células $\mathrm{CD}^{+} 4^{+}$provenientes de pacientes com $\mathrm{LMC}^{71}$.

Em linhagens celulares SET-2 e HEL com a mutação JAK2 ${ }^{\mathrm{V} 617 \mathrm{~F}}$, metformina inibiu a proliferação e induziu a apoptose celular, indicando seu potencial citotóxico, inibiu a fosforilação de JAK2 e STAT5 e aumentou a produção de EROs ${ }^{72}$. Similarmente, nosso grupo de pesquisa evidenciou que, em linhagens celulares $\mathrm{JAK} 2^{\mathrm{V} 617 \mathrm{~F}}$, a metformina reduziu a proliferação celular, o percentual de células na fase $\mathrm{G} 2 / \mathrm{M}$ e a capacidade clonogênica. A metformina também inibiu a fosforilação de STAT3 e STAT5. Em modelo murino JAK2 ${ }^{\mathrm{V} 617 \mathrm{~F}}$ observou-se que a metformina foi bem tolerada in vivo, reduziu a esplenomegalia e o percentual de progenitores eritroides no baço. Em células HEL e SET-2, a ação combinada de metformina com ruxolitinibe aumentou a apoptose celular quando comparada à monoterapia e reduziu a 
proliferação celular ${ }^{73}$. Assim, nosso grupo de pesquisa lança luz sob novas oportunidades terapêuticas complementares em neoplasias hematológicas e se empenha no avanço de modelos pré-clínicos nesse grupo de doenças.

A compreensão dos mecanismos pelos quais as CTH de NMP tornam-se predominantes na MO ainda possui grandes lacunas a serem preenchidas. A ineficiência dos inibidores de JAK2 na eliminação efetiva do clone mutado das CTH sugere que novas abordagens terapêuticas com múltiplos alvos sejam necessárias. O progresso nesse campo depende do desenvolvimento de novas terapias e do desenvolvimento de ensaios pré-clínicos que prevejam a avaliação biológica das $\mathrm{CTH}^{74}$. Assim, as biguanidas surgem como um potencial agente antineoplásico para auxiliar no tratamento de neoplasias hematológicas. 


\section{OBJETIVOS}

\subsection{Objetivo Geral}

Investigar os efeitos antineoplásicos da fenformina em neoplasias mieloproliferativas $\mathrm{JAK} 2^{\mathrm{V} 617 \mathrm{~F}}$.

\subsection{Objetivos específicos}

1. Avaliar o efeito da fenformina in vitro em modelos celulares de NMP JAK2 ${ }^{\mathrm{V} 617 \mathrm{~F}}$ quanto à viabilidade e apoptose celular.

2. Em camundongos $\mathrm{JAK} 2^{\mathrm{V} 617 \mathrm{~F}}$ tratados com veículo ou fenformina:
a) Avaliar a eficiência terapêutica da utilização da fenformina in vivo quanto a tolerabilidade ao tratamento e resposta hematológica;
b) Quantificar os precursores eritroides no baço e medula óssea;
c) Estimar a frequência de células-tronco precursoras e progenitoras hematopoéticas;
d) Avaliar os aspectos histopatológicos de baço e medula óssea;
e) Analisar a capacidade clonogênica.

3. Em modelo de transplante com células da medula óssea de camundongos JAK2 $2^{\mathrm{V} 617 \mathrm{~F}}$ tratadas ex vivo com fenformina, metformina ou veículo:
a) Avaliar a capacidade do tratamento ex vivo com fenformina em modular os parâmetros hematimétricos;
b) Investigar a capacidade de autorrenovação da CTH;

4. Em células primárias de pacientes $\mathrm{JAK} 2^{\mathrm{V} 617 \mathrm{~F}}$ submetidas ao tratamento in vitro com veículo ou fenformina:

a) Analisar a capacidade do tratamento in vitro com fenformina em modular a formação de colônias. 
MATERIAIS E MÉTODOS 


\section{MATERIAL E MÉTODOS}

\subsection{Casuística}

Amostra utilizada foi obtida de paciente com diagnostico de MF pós-PV JAK2 ${ }^{\mathrm{V} 617 \mathrm{~F}}$, sexo feminino, em seguimento regular no Ambulatório de Hematologia do Hospital das Clínicas da Faculdade de Medicina de Ribeirão Preto da Universidade de São Paulo (HCFMRPUSP). A coleta e utilização de amostra biológica humana foi aprovada perante submissão do projeto ao Comitê de Ética em Pesquisa (CEP) do HCFMRP-USP (Parecer 3.455.210) (ANEXO A).

\subsection{Linhagens Celulares}

Foi utilizada a linhagem celular humana SET-2, proveniente de LMA secundária à TE, heterozigota para JAK2 $2^{\mathrm{V} 617 \mathrm{~F}} 75$. SET-2 recapitula um modelo de NMP com fenótipo para TE e com transformação leucêmica megacarioblástica ${ }^{76}$. A linhagem foi obtida a partir da doação da Prof. ${ }^{a}$ Dr. ${ }^{a}$ Fabíola Attié de Castro da Faculdade de Ciências Farmacêuticas de Ribeirão Preto da Universidade de São Paulo (FCFRP-USP); e foi cultivada em RPMI suplementado com 20\% de soro fetal bovino (SFB) com 1\% Penicilina e Estreptomicina (GIBCO, EUA).

\subsection{Inibidor Farmacológico}

Para realização dos experimentos, o cloridrato de fenformina, a partir daqui referido como fenformina, foi adquirido da Sigma-Aldrich (EUA). A fenformina foi diluída em PBS e armazenada em estoque a uma concentração de $100 \mathrm{mM}$ em freezer $-20^{\circ} \mathrm{C}$ em alíquotas de $1 \mathrm{~mL}$.

\subsection{Ensaio de viabilidade celular}

Para análise da viabilidade celular, foi utilizado o teste de Methylthiazoletetrazolium (MTT) (Sigma, EUA). Aproximadamente $1 \times 10^{5}$ células por $\mathrm{mL}$ foram cultivadas em placa de 96 poços em meio RPMI suplementado com $20 \%$ de SFB. O cultivo foi feito com $100 \mu \mathrm{L}$ ppoço na presença ou não de fenformina em diferentes concentrações $(\varnothing ; 0,5 \mathrm{mM} ; 1 \mathrm{mM}, 2 \mathrm{mM}$ ou $5 \mathrm{mM}$ ) por 24, 48 ou 72 horas. Após o período determinado, adicionou-se $10 \mu \mathrm{L}$ de uma solução 
de MTT $(5 \mathrm{mg} / \mathrm{mL})$ em cada poço com posterior incubação à $37^{\circ} \mathrm{C}$ durante 4 horas. A reação foi interrompida por meio da adição de $100 \mu \mathrm{L}$ de $0,1 \mathrm{~N} \mathrm{HCl}$ em isopropanol. A viabilidade celular foi determinada utilizando o leitor de microplacas iMark (Biorad, EUA) por meio da mensuração da absorbância à 570nm. Todas as condições foram testadas em pelo menos cinco réplicas biológicas. Após isso, utilizando regressão linear foram calculados os valores de $\mathrm{IC}_{50}$ usando os dados obtidos pelos ensaios de viabilidade celular. $\mathrm{O}$ valor de $\mathrm{IC}_{50}$ foi projetado por meio do programa Calcusyn (Biosoft, Cambridge, Reino Unido) e a curva dose-resposta no programa GraphPad Prism 8 (GraphPad Software, Inc., San. Diego, CA, EUA).

\subsection{Análise da apoptose celular por Anexina-V e 7-AAD}

Células SET-2 foram cultivadas em placas de 12 poços, aproximadamente $1 \times 10^{5}$ células por $\mathrm{mL}$, e submetidas a diferentes concentrações de fenformina $(\varnothing ; 0,5 \mathrm{mM} ; 1 \mathrm{mM} ; 2 \mathrm{mM}$ e $5 \mathrm{mM}$ ) durante 24, 48 ou 72 horas. As células foram lavadas uma vez com 1mL de PBS, submetidas à centrifugação por 5 minutos a velocidade de $445 \mathrm{~g}$. O sobrenadante foi descartado e as células foram ressuspendidas em 100uL de tampão de ligação contendo 0,5uL de AnexinaV conjugada a APC e 2uL de 7-AAD (Becton-Dickinson, EUA). Após o período de 15 minutos de incubação na ausência de luz e em temperatura ambiente, acrescentou-se 100uL de tampão de ligação e as amostras foram analisadas no citômetro FACSCalibur. Dez mil aquisições foram feitas para cada amostra. Todas as condições foram testadas em pelo menos três réplicas biológicas.

\subsection{Modelo murino com a mutação JAK2 ${ }^{\text {V617F }}$}

O modelo murino com mutação JAK2 ${ }^{\mathrm{V} 617 \mathrm{~F}}\left(\mathrm{JAK} 2{ }^{\mathrm{wt} / \mathrm{Fl}}\right)$ foi cedido pela pesquisadora Dr. ${ }^{\text {a }}$ Ann Mullally ${ }^{77}$ e modificado e estabelecido no Centro de Terapia Celular (CTC) do Hemocentro de Ribeirão Preto pela prof. ${ }^{\text {a }}$ Dr. ${ }^{a}$ Lorena Lobo de Figueiredo-Pontes (FAPESP 2015/21866-1). O controle da expressão da mutação no modelo murino é exercido pelo promotor murino endógeno de JAK2. Os animais JAK2 ${ }^{\mathrm{wt} / \mathrm{Fl}}$ não expressam o JAK2 mutado e não tem fenótipo clínico, pois a expressão da mutação está sob regulação da enzima crerecombinase. Após cruzamento de $\mathrm{JAK} 2^{\mathrm{wt} / \mathrm{Fl}}$ com animais transgênicos $\mathrm{Vav} / \mathrm{Cre}$, nos quais a cre-recombinase é expressa sob o controle do promotor murino Vav, especificamente em células das linhagens hematopoética e endotelial, a expressão da JAK2 ${ }^{\mathrm{V} 617 \mathrm{~F}}$ é obtida. A recombinação 
cre ocorre em duas etapas, uma que remove o éxon WT e a outra que coloca V617F em orientação normal para a transcrição. A estratégia utilizada para produção dos animais geneticamente modificados foi previamente descrita ${ }^{78}$.

\subsection{Tratamento in vivo de fenformina em modelo murino de NMP JAK2 ${ }^{\text {WT/Fl- }}$} Vav/Cre

Após aprovação do projeto de pesquisa pelo Comitê de Ética no Uso de Animais (CEUA) da Faculdade de Medicina de Ribeirão Preto (FMRP) (protocolo 183/2018) (ANEXO B), camundongos receptores Pep/boy C57BL/6 CD45.1 foram letalmente irradiados com 7Gy de raios $\mathrm{X}$, divididas em 2 doses com intervalo de 4 horas. Camundongos JAK2 ${ }^{\mathrm{WT} / \mathrm{Fl}}{ }_{-} \mathrm{Vav} / \mathrm{Cre}$ CD45.2 doadores foram eutanasiados com sobredose de cetamina $(300 \mathrm{mg} / \mathrm{kg})$ e xilazina $(30 \mathrm{mg} / \mathrm{kg})$, e submetidos a maceração de fêmures, tíbias e coluna vertebral para obtenção da MO. Cinco milhões $\left(5 \times 10^{6}\right)$ de células totais da $\mathrm{MO}$ dos camundongos doadores foram injetadas via plexo retro-ocular nos camundongos receptores Pep/boy C57BL/6 CD45.1 letalmente irradiados (Figura 1). Após o transplante de medula óssea (TMO), realizou-se antibioticoterapia profilática nos camundongos transplantados através da administração de enrofloxacino $5 \mathrm{gm} / \mathrm{kg}$ durante 05 dias via subcutânea.

O quimerismo dos animais transplantados foi analisado por citometria de fluxo pela marcação dos leucócitos em SP utilizando os marcadores FITC-CD45.1 e PE-CD45.2 (BectonDickinson, EUA) 4 semanas após o TMO. Os grupos experimentais, tratados e controles, foram pareados segundo peso, quimerismo e hemograma. A fenformina $(40 \mathrm{mg} / \mathrm{kg})$ foi administrada diariamente, via intraperitoneal (IP), durante 7 semanas. Os valores de referência dos parâmetros hematimétricos utilizados foram definidos pelo The Jackson Laboratory (Tabela 1). O quimerismo calculado pelo percentual de células marcadas positivamente para os anticorpos CD45.1 ou CD45.2. Selecionou-se as células viáveis por distribuição de tamanho (Forward scatter [FSC], em inglês) e complexidade interna (Side scatter [SSC], em inglês). Os singlets foram selecionados, essa seleção consiste na exclusão de agregados celulares que possam ter passado pelo laser do citômetro e contabilizados como um único evento ${ }^{79}$. Por último, as células marcadas positivamente para CD45.1 ou CD45.2 foram selecionadas (Figura 2). 
Tabela 1. Parâmetros hematimétricos normais para camundongos Pep/boy C57BL/6-CD45.1

\begin{tabular}{|c|c|c|}
\hline & Fêmeas & Machos \\
\hline Leucócitos, $10^{3} / \mathrm{uL}$ (min-max) & $3.6-5.4$ & $3.4-3.6$ \\
\hline Eritrócitos, $10 \%$ uL (min-max) & $10.7-11$ & $10.9-10.9$ \\
\hline Hemoglobina, g/dL (min-max) & $15.9-16.0$ & $15.6-16.0$ \\
\hline Hematócrito, \% (min-max) & $49.1-49.2$ & $48.6-50.3$ \\
\hline Plaquetas, $10^{3} / \mathrm{uL}$ (min-max) & $994-1063$ & $1087-1109$ \\
\hline
\end{tabular}

Fonte: The Jackson Laboratory

Figura 1 - Indução do modelo murino com a mutação em JAK2 para tratamento in vivo com fenformina ou veículo

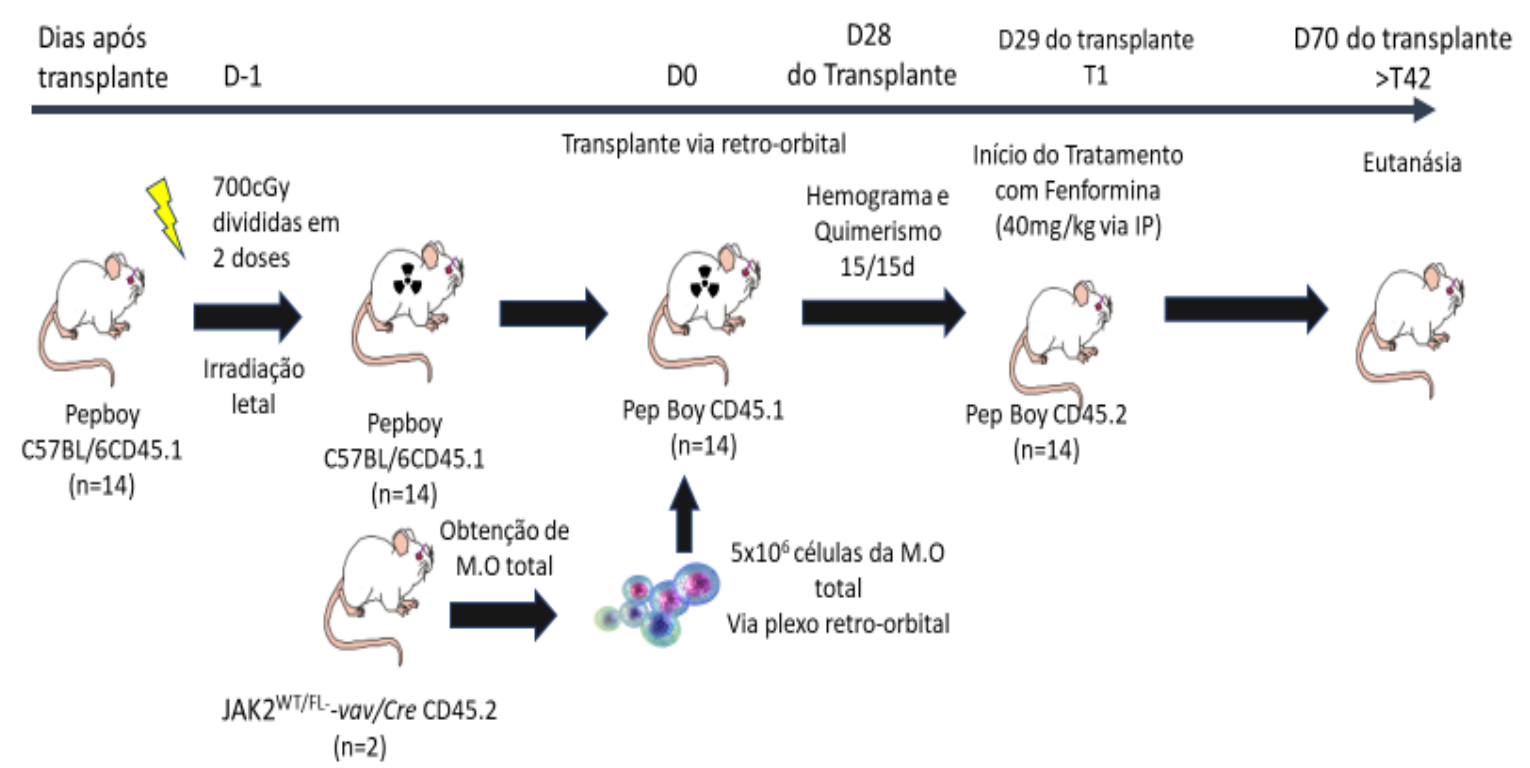

Figura 1 - Camundongos Pepboy C57BL/6 CD45.1 foram letalmente irradiados com 7Gy de raios x. Camundongos $\mathrm{JAK}_{2}{ }_{\mathrm{WT} / \mathrm{Fl}^{-}}-$Vav/Cre CD45.2 foram eutanasiados, fêmures, tíbia e coluna vertebral foram separados para obtenção da MO. $5 \times 10^{6}$ células totais da MO dos animais JAK2 ${ }^{\mathrm{WT} / \mathrm{Fl}-}$-Vav/Cre CD45.2 foram injetadas via plexo retro-ocular dos camundongos Pepboy C57BL/6 CD45.1 para indução de NMP. Após 4 semanas do TMO, os animais foram submetidos a análise do quimerismo (CD45.2/CD45.1) e do hemograma para divisão em grupos que seriam tratados com fenformina $40 \mathrm{mg} / \mathrm{kg} / \mathrm{dia}$ via intraperitoneal (IP) e grupos que receberiam apenas veículo (PBS; $100 \mu \mathrm{L} /$ dia via IP). 
Figura 2 -Método de análise por citometria de fluxo do quimerismo dos animais receptores PepBoy C57BL/6 CD45.1 submetidos ao transplante de medula óssea de camundongos doadores JAK2 ${ }^{\mathrm{WT} / F \mathrm{~F}}$ Vav/Cre CD45.2.
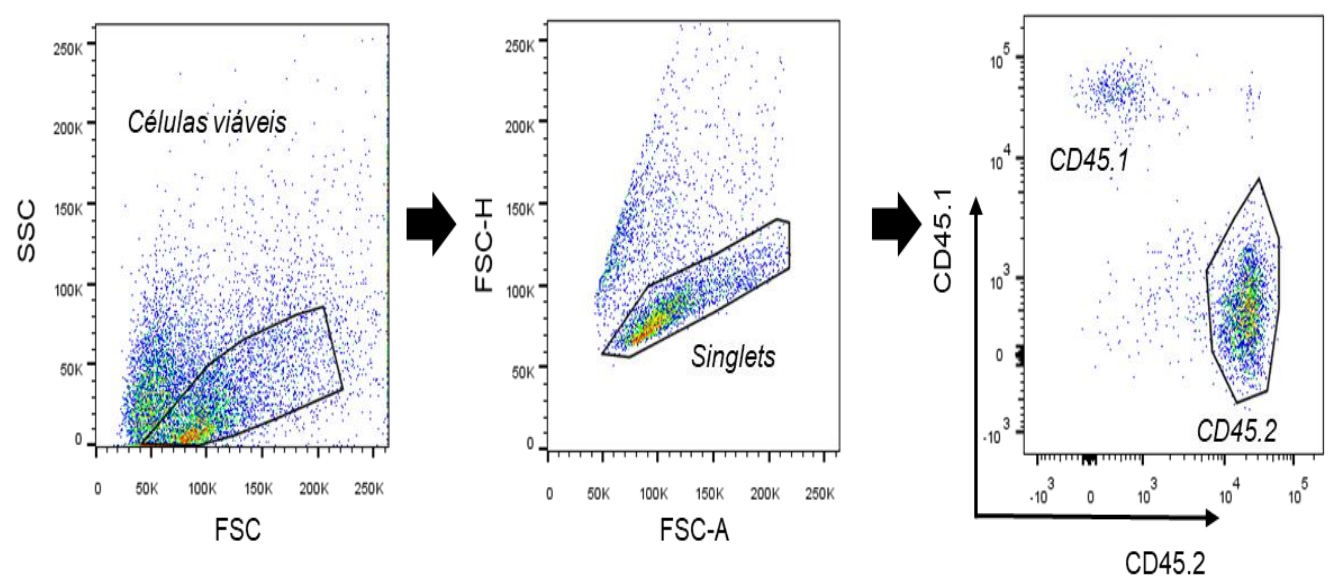

Figura 2. Demonstração do método utilizado por citometria de fluxo para identificação das células que foram marcadas com os anticorpos CD45.1 e CD45.2. O primeiro quadrante, na esquerda para a direita, observa-se a seleção de células viáveis provenientes do SP dos camundongos submetidos ao transplante de medula óssea. A seleção é feita pela complexidade (SSC) e pelo tamanho das células (FSC). No segundo quadrante encontra-se a separação de agregados celulares que possam ter sido confundidos pelo citômetro como uma única célula, então a seleção é feita pela área celular (FSC-A) e pela altura (FSC-H). No terceiro quadrante, na parte inferior direita estão as células que foram positivamente marcadas para o anticorpo CD45.2. As marcações CD45.1 e CD45.2 identificam as células dos animais receptores Pep/Boy C57BL/6 CD45.1 e dos animais doadores JAK2 ${ }^{\text {WT/FI- }}$-Vav/Cre CD45.2, respectivamente. Fonte: ABA, Silva.

Após 7 semanas de tratamento, os animais foram eutanasiados e as células da MO foram obtidas através de flushing de fêmures, tíbias e coluna vertebral e filtradas em Cell Strainer® (Becton-Dickinson, EUA) de $70 \mu \mathrm{m}$ para que fossem retirados quaisquer resquícios sólidos. O baço foi cirurgicamente removido e submetido à maceração do tecido Cell Strainer® para obtenção de células ou submetido à solução de formalina 10\% para posterior análise histológica. As células da MO e do baço foram mantidas sob refrigeração em PBS com SFB 2\%. As células foram submetidas ou não à lise de eritrócitos, conforme necessário, através de choque hipotônico com solução de cloreto de amônio e foram ressuspendidas em PBS para os ensaios de citometria de fluxo ou clonogenicidade.

\subsection{Análise do hemograma}

O hemograma dos camundongos foi avaliado quinzenalmente pela punção da veia facial lateral, o sangue foi coletado em microtubos de $1,5 \mathrm{~mL}$ contendo $15 \mathrm{uL}$ de heparina como 
anticoagulante. A avaliação dos parâmetros hematimétricos foi realizada por meio do contador hematológico automatizado (ABX Micro 60, Horiba Medical, Japão).

\subsection{Quantificação das células-tronco hematopoéticas e precursores hematopoéticos}

Para estimação das $\mathrm{CTH}, 1 \times 10^{6}$ células submetidas à lise de eritrócitos e ressuspendidas em PBS foram incubadas por 15 minutos com anticorpos específicos, lavadas e ressuspendidas em PBS para análise por citometria de fluxo. As células maduras foram identificadas pela marcação com anticorpos biotinilados definidores de linhagem Ter119, B220, CD8a, Gr1 e CD11b. Em seguida, as células foram marcadas com anticorpos fluorescentes estreptavidinaPerCP, C-Kit ${ }^{\mathrm{Hi}}$-APC-Cy7, Sca1-APC, para identificação das populações LSK $\left(\mathrm{Lin}^{-} \mathrm{Sca}^{1+}{ }^{1+}{ }^{-}\right.$ $\mathrm{Kit}^{\mathrm{Hi}}$ ) e do progenitor mieloide ( $\left.\mathrm{Lin}^{-} \mathrm{Scal}^{-} \mathrm{c}-\mathrm{Kit}^{\mathrm{Hi}}\right)$. DAPI foi utilizado como marcador de viabilidade celular.

As subpopulações de células-tronco e progenitoras hematopoéticas foram avaliadas como frações da população LSK $\left(\mathrm{Lin}^{-} \mathrm{Sca}^{1+} \mathrm{c}-\mathrm{Kit}^{\mathrm{Hi}}\right)$, pelos imunofenótipos: células-tronco de longo prazo (LT-HSC) CD48-CD150 ${ }^{+}$, células-tronco de curto prazo (ST-HSC) $\mathrm{CD} 48^{+} \mathrm{CD} 150^{+}$ e progenitores multipotentes (MPP) $\mathrm{CD}^{+} 8^{+} \mathrm{CD} 150^{-}$. Para quantificação dos precursores

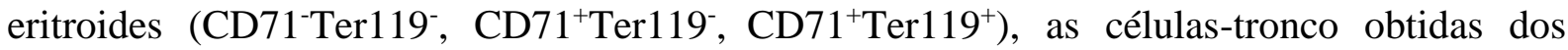
animais tratados ou não com fenformina não foram submetidas à lise de eritrócitos e foram marcadas com os anticorpos definidores de linhagem eritroides CD71 e Ter119 (Tabela 2). A aquisição dos eventos foi realizada em citômetro FACSCalibur (Becton-Dickinson, EUA) e a análise feita usando o software FlowJo v.9.6.3. (Treestar, Inc., EUA).

Tabela 2. Imunofenótipo de células tronco e progenitoras hematopoéticas avaliados.

\begin{tabular}{|c|c|}
\hline Linhagem Celular & Anticorpos \\
\hline Progenitor Mieloide & $\operatorname{Lin}^{-} \mathrm{Sca}^{+}{ }^{+} \mathrm{c}-\mathrm{Kit}^{\mathrm{Hi}}$ \\
\hline Progenitores Eritroide & CD71 e Ter119 \\
\hline Eritroblasto Ortocromático & CD71 $1^{\text {high }}$, Ter119 $9^{\text {high }}$ e FSC ${ }^{\text {high }}$ \\
\hline Reticulócitos & CD71 ${ }^{\text {high }}$, Ter119 $9^{\text {high }}$ e FSC ${ }^{\text {low }}$ \\
\hline Eritrócitos & CD71 ${ }^{\text {low }}$, Ter119 $9^{\text {high }}$ e FSC ${ }^{\text {low }}$ \\
\hline \multicolumn{2}{|l|}{ Célula-tronco Hematopoética } \\
\hline Progenitor Multipotente & $\mathrm{Lin}^{-} \mathrm{Sca}-1^{+} \mathrm{c}-\mathrm{Kit}^{+} \mathrm{CD} 48^{+} \mathrm{CD} 150^{-}$ \\
\hline Long-term & Lin ${ }^{-} \mathrm{Sca}-1^{+} \mathrm{c}-\mathrm{Kit}^{+} \mathrm{CD} 48^{-}$e CD $150^{+}$ \\
\hline Short-term & Lin ${ }^{-S c a}-1^{+} \mathrm{c}-\mathrm{Kit}^{+} \mathrm{CD} 48^{+}$e CD $150^{+}$ \\
\hline
\end{tabular}

Fonte:Morrison $(1997)^{80}$ e Koulnis $(2011)^{81}$. 


\subsection{Avaliação histológica do baço e medula óssea}

Para avaliação histológica, um segmento da coluna vertebral e uma porção do baço dos camundongos foram obtidos após eutanásia e armazenados em formalina a 10\% e processados em parafina. Um segmento da coluna vertebral foi descalcificada utilizando EDTA e embebida em parafina. Os cortes foram reidratados com lavagens seriadas de etanol e Tris (TBS; 10mM Tris com pH 7.4, 150mM NaCl) com Tween-20 (0,05\%). A análise foi realizada através da coloração com hematoxilina e eosina para análise dos aspectos arquiteturais e distribuição celular ou pelo método de Gömöri para avaliação da fibrose reticulínica. Esta etapa foi realizada em colaboração com o Prof. Dr. Fernando Chahud do Departamento de Patologia e Medicina Legal da FMRP-USP.

\subsection{Avaliação da capacidade clonogênica de células progenitoras hematopoéticas}

Para análise da formação espontânea de colônias murinas independente da presença de EPO, $1 \times 10^{4}$ células de MO provenientes da coluna vertebral dos animais foram plaqueadas em 250uL de metilcelulose. Células de cada animal foram cultivadas em duplicata em placas de 24 poços, mantidas em estufa com $5 \%$ de $\mathrm{CO}_{2}$ a $37^{\circ} \mathrm{C}$. As colônias foram analisadas 10 dias após o plaqueamento, conforme orientações do fabricante, e contadas a partir de suas características morfológicas. As unidades formadoras de colônias foram classificadas como granulocítica, macrofágicas e granulocítica-macrofágicas (CFU-G, CFU-M. CFU-GM, respectivamente); unidades formadoras de colônias de progenitores eritroides (CFU-E) e em unidades formadoras de colônias de progenitores multipotentes (CFU-GEMM) $)^{82}$.

\subsection{Avaliação do efeito do tratamento ex vivo da fenformina na capacidade de} autorrenovação de células-tronco e progenitoras hematopoéticas em modelo murino NMP $\mathrm{JAK2}^{\mathrm{WT} / \mathrm{Fl}-\text {-Vav/Cre. }}$

Para análise do efeito do tratamento ex vivo da fenformina e metformina na capacidade de enxertia das $\mathrm{CTH}$ em camundongos, a MO total de um camundongo JAK2 ${ }^{\mathrm{WT} / \mathrm{Fl}}-\mathrm{Vav} / \mathrm{Cre}$ CD45.2 foi obtida por maceração de fêmures, tíbia e coluna vertebral após a eutanásia e submetidas ao tratamento ex vivo com $1 \mathrm{mM}$ de fenformina ou metformina (10mM) durante 18 horas em meio de cultura Alpha-MEM (Gibco, EUA) com adição de 40uL de IL3 (10ng/mL), 
40uL de IL6 (10ng/mL) e 20uL de SCF (50ng/mL) (Prepotech, EUA), SFB 5\% e soro fetal equino (SFE) (Vitrocell, Brasil) 5\% e $\beta$-Mercaptoetanol 1\%. Após 18 horas de cultivo com fenformina, metformina ou veículo, as células foram retiradas do meio de cultura, lavadas com PBS e centrifugadas por 5 minutos a $690 \mathrm{~g}$. Aproximadamente $1 \times 10^{6}$ células foram injetadas via plexo retro-ocular em cada camundongo Pep/Boy C57BL/6 CD45.1 (Figura 3). Previamente à infusão das células e no mesmo dia, os animais receptores foram submetidos a uma única dose de irradiação subletal de 3.5Gy. Os animais receptores foram avaliados após o TMO quanto ao hemograma e quimerismo, a cada 15 dias no primeiro mês, a cada 4 semanas até quarto mês. $\mathrm{O}$ hemograma e o quimerismo foram avaliados conforme descrito no item 3.7. Os animais receptores foram mantidos vivos para avaliação futura do quimerismo após 1 ano do TMO.

\section{Figura 3 - Representação do modelo de transplante com células JAK2 ${ }^{\text {WT/FL---Vav/Cre CD45.2 tratadas }}$ ex vivo com fenformina, metformina ou veículo para transplante em camundongos Pepboy C57BL/6 \\ CD45.1}

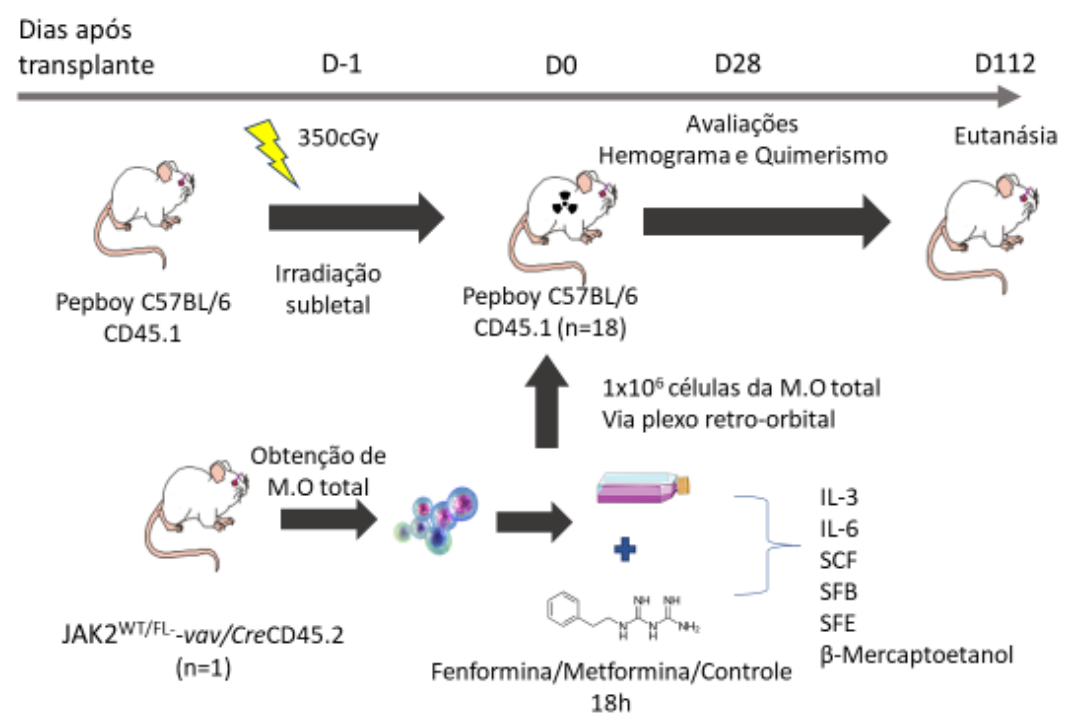

Figura 3 -Animais Pepboy C57BL/6 CD45.1 foram irradiados subletalmente com raios x. A medula óssea (MO) dos animais JAK2 ${ }^{\mathrm{WT} / \mathrm{Fl}^{-}}-\mathrm{Vav} / \mathrm{Cre}$ CD45.2 foi obtida por crushing de fêmures, tíbias e coluna vertebral dos animais. As células da MO foram cultivadas durante $18 \mathrm{~h}$ na presença ou ausência de fenformina, metformina ou veículo (PBS). Após o período de cultivo, as células foram transplantadas nos camundongos Pepboy C57BL/6 previamente irradiado subletalmente. Os animais foram acompanhados quanto ao hemograma e quimerismo a cada 15 dias durante o primeiro mês e posteriormente a cada 30 dias até o $4^{\circ}$ mês.

\subsection{Avaliação da capacidade clonogênica de células primárias de paciente} JAK2 $2^{\mathrm{V} 617 \mathrm{~F}}$

Células da MO de paciente com MFP pós-PV JAK2 ${ }^{\mathrm{V} 617 \mathrm{~F}}$ foram colhidas em seringas contendo heparina sódica como anticoagulante e foram submetidas à lise de eritrócitos durante 10 minutos em refrigeração com tampão contendo cloreto de amônio. O procedimento foi 
repetido até que os eritrócitos visíveis fossem lisados. As células mononucleares da MO foram separadas usando o gradiente de densidade Ficoll-Hypaque (Sigma-Aldrich, EUA). Aproximadamente $4 \mathrm{~mL}$ de Ficoll-Hypaque foi utilizado para cada $8 \mathrm{~mL}$ de amostra, a amostra foi centrifugada a $690 \mathrm{~g}$ durante 20 minutos sem aceleração e sem freio. As células foram contadas para que fosse possível prosseguir com os experimentos utilizando a quantidade de células necessárias em cada situação.

O ensaio de formação espontânea de colônias foi realizado em meio semissólido de metilcelulose (MethoCult H4434; StemCell Technologies Inc., Canada). Aproximadamente $3 \times 10^{4}$ células $/ \mathrm{mL}$ foram plaqueadas em duplicata em $500 \mathrm{uL}$ de metilcelulose utilizando uma placa de 12 poços na presença e/ou ausência de fenformina (Ø; $1 \mathrm{mM}$ ou $2 \mathrm{mM})$. As colônias foram mantidas em câmara de $\mathrm{CO}_{2} 5 \%$ a $37^{\circ} \mathrm{C}$ e submetidas a contagem e identificação das colônias após 10 dias de cultivo, conforme orientações do fabricante do meio semissólido ${ }^{82}$.

\subsection{Forma de análise de resultados}

Os dados foram analisados usando o GraphPad Prism 5 (GraphPad Software, Inc., EUA). Para comparações entre as médias dos grupos experimentais foram utilizados os testes Mann-Whitney, One-way ANOVA ou Two-way ANOVA, conforme apropriado. Todos testes utilizaram nível de significância de $\alpha<0.05$. 
RESULTADOS 


\section{RESULTADOS}

\subsection{Fenformina reduz a viabilidade e aumenta apoptose em células JAK2 ${ }^{\mathrm{V} 617 \mathrm{~F}}$}

Células SET-2 foram tratadas ou não com a fenformina em diferentes concentrações $(\varnothing$; $0.5 \mathrm{mM} ; 1 \mathrm{mM} ; 2 \mathrm{mM}$ ou $5 \mathrm{mM})$ e diferentes tempos de exposição (24h, $48 \mathrm{~h}$ ou $72 \mathrm{~h}$ ). A viabilidade celular foi avaliada através do ensaio de MTT. O cálculo de $\mathrm{IC}_{50}$ foi realizado pelo programa CalcuSyn (Biosoft, Reino Unido) utilizando os dados de viabilidade obtidos pelos ensaios de MTT. O programa nos fornece informações acerca da dose mínima de fenformina capaz de reduzir a população celular em $50 \%$. A $\mathrm{IC}_{50}$ da fenformina foi maior que $2 \mathrm{mM}$, $1.79 \mathrm{mM}$ e $0.79 \mathrm{mM}$ para 24, 48 e 72 horas, respectivamente (Figura 4). A apoptose celular foi avaliada por citometria de fluxo por meio da marcação positiva das células com os anticorpos Anexina-V e 7AAD. A fenformina induziu a apoptose celular de forma dose e tempo dependente, o aumento do percentual de células em apoptose foi observado em células expostas à fenformina a $5 \mathrm{mM}$; $\geq 2 \mathrm{mM}$; e $\geq 1 \mathrm{mM}$ após 24,48 e 72 horas de tratamento $(p<0.05)$, respectivamente. Fenformina 5mM induziu apoptose celular em 49\%, 67\% e 75\% da população de células avaliadas após 24, 48 e 72 horas de exposição, respectivamente (Figura 5 e Figura 6).

Figura 4 - Curvas de dose-resposta, efeito médio e comparação de dose-resposta com relação ao tempo de exposição das células SET-2 à fenformina.

SET-2

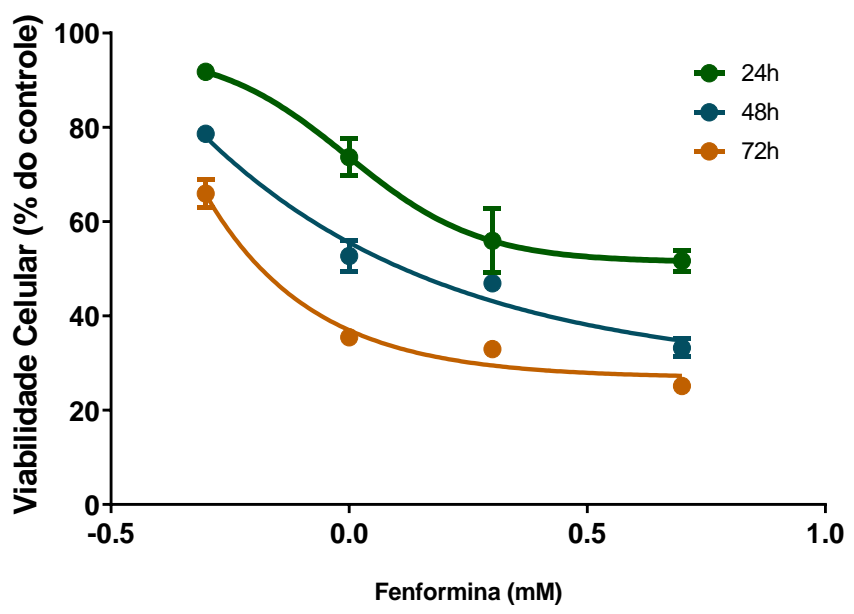

Figura 4. Curva dose-resposta indicam o efeito exercido pela fenformina em relação à concentração. As doses utilizadas estão representadas no eixo $\mathrm{X}$ e os efeitos percentuais observados de redução de viabilidade encontramse representados no eito Y. A curva representa a média das réplicas do efeito da fenformina nos diferentes tempos de exposição e às diferentes concentrações. 
Figura 5 - Apoptose das células SET-2 após exposição à fenformina durante 24, 48 ou $72 \mathrm{~h}$ em diferentes concentrações

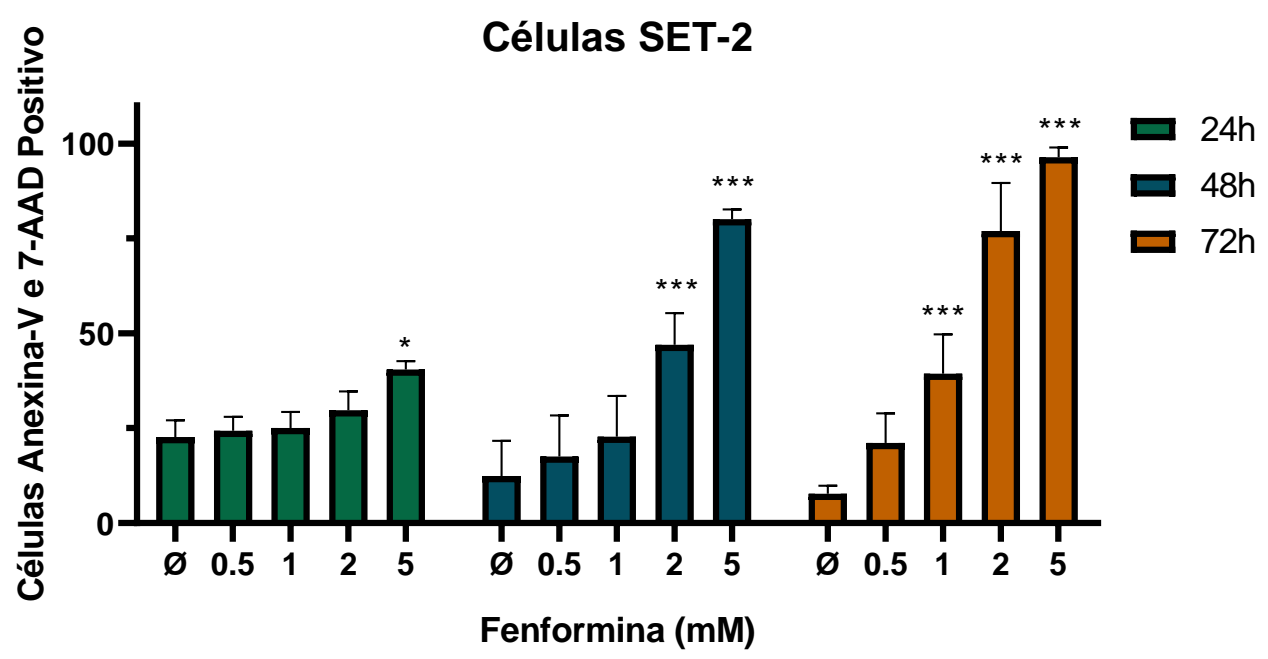

Figura 5 - Fenformina aumenta o percentual de células em apoptose de forma dose e tempo-dependente. Os gráficos apresentam as médias com desvio padrão das células SET-2 tratadas com fenformina em diferentes concentrações por 24,48 ou $72 \mathrm{~h}$. A apoptose foi avaliada por citometria de fluxo por meio da marcação das células com Anexina -V e 7-AAD. Os resultados apresentados nos gráficos são referentes a quatro experimentos independentes. Os valores de $p$ são apresentados como $* p<0.05 ; * * p<0.01$; *** $p<0.001$ em relação ao controle $(\varnothing)$. Teste Two-way ANOVA

\subsection{Tratamento com fenformina in vivo em modelo murino de NMP induzida por} JAK2 ${ }^{\text {WT/FI--Vav/Cre CD45.2 }}$

Após o TMO de camundongos JAK2 ${ }^{\mathrm{WT} / \mathrm{Fl}}-$-Vav/Cre CD45.2 em camundongos receptores Pepboy C57BL/6 CD45.1, os camundongos receptores receberam antibioticoterapia profilática e foram acompanhados semanalmente até a $4^{\circ}$ semana. Na semana 4 pós-transplante, os receptores foram submetidos à avaliação do hemograma e quimerismo (CD45.2/CD45.1) (Tabela 3). Os camundongos receptores foram randomizados para receberem tratamento com veículo (PBS; $100 \mu \mathrm{L} / \mathrm{dia})$ ou fenformina $(40 \mathrm{mg} / \mathrm{kg} / \mathrm{dia}$ em $100 \mu \mathrm{L})$ intraperitonealmente; os dois grupos apresentaram parâmetros hematimétricos e percentual de quimerismo semelhantes (Tabela 4). A efetividade do transplante de MO foi atestada pela presença de mais de $80 \%$ de células CD45.2 positivas (Figura 7). O fenótipo de PV foi evidenciado pela contagem de hemoglobina e hematócrito superiores aos valores de referência preconizados pelo The Jackson Laboratory (Tabela 4). 
Figura 6 - Efeitos do tratamento com fenformina em diferentes concentrações na apoptose celular das células SET-2 durante 24, 48 e 72h.

\section{Fenformina}
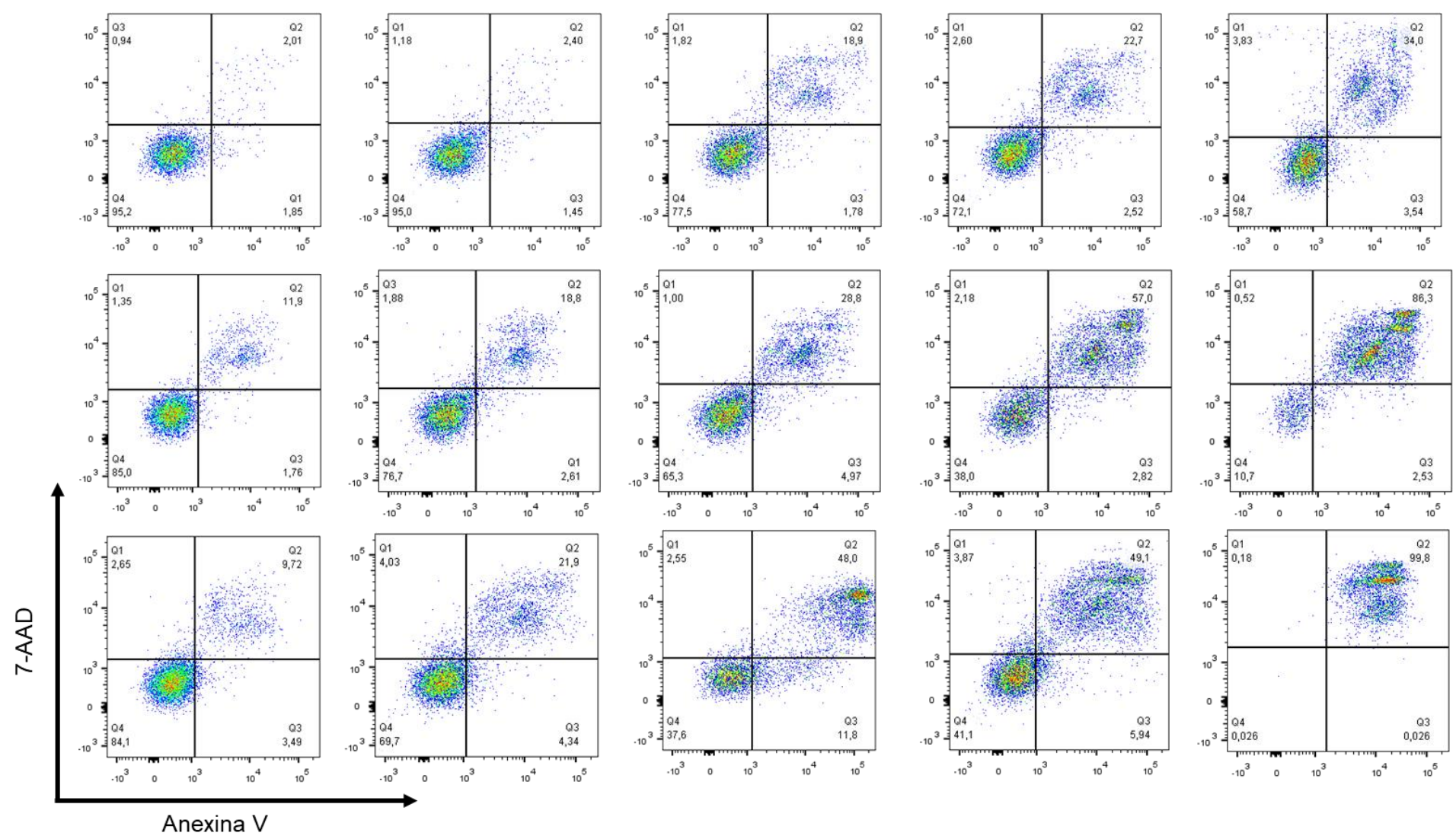

Figura 6 - Gráficos de pontos representativos para análise de apoptose em células SET-2 tratadas com veículo ou fenformina. Células SET-2 foram tratadas com veículo (PBS) ou diferentes doses de fenformina, durante 24, 48 ou 72 horas. O quadrante inferior direito indica as células Anexina-V (APC) positivas, o quadrante superior esquerdo as células positivas para 7-AAD e o quadrante superior direito representa as células Anexina- $\mathrm{V}$ positivas e 7-AAD positivas, foram consideradas as células Anexina-V e 7-AAD positivas. 
Tabela - 3. Parâmetros hematimétricos dos camundongos submetidos ao TMO com células provenientes de animais JAK2 ${ }^{\mathrm{WT} / \mathrm{Fl}}$-Vav/Cre $\mathrm{CD} 45.24$

\begin{tabular}{|c|c|c|c|c|c|c|}
\hline Animais & $\begin{array}{c}\text { Leucócitos } \\
\left(10^{6} / \mathrm{uL}\right)\end{array}$ & $\begin{array}{c}\text { Eritrócitos } \\
\left(10^{6} / \mathbf{u L}\right)\end{array}$ & $\begin{array}{c}\text { Hemoglobina } \\
(\mathrm{g} / \mathrm{dL})\end{array}$ & $\begin{array}{c}\text { Hematócrito } \\
(\%)\end{array}$ & $\begin{array}{c}\text { Plaquetas } \\
\left(10^{3} / \mathrm{uL}\right)\end{array}$ & $\begin{array}{c}\text { Quimerismo } \\
(\%)\end{array}$ \\
\hline Valores de Referência & $3.6-5.4$ & 10.7-11 & 15.9-16.0 & $49.1-49.2$ & $994-1063$ & $>80$ \\
\hline \multicolumn{7}{|l|}{ Grupo Controle } \\
\hline $\mathrm{C} 1.2$ & 8.1 & 11.07 & 16.9 & 53.9 & 534 & 91.6 \\
\hline $\mathrm{C} 2.6$ & 9.6 & 12.42 & 19.5 & 62.9 & 512 & 92.8 \\
\hline $\mathrm{C} 2.7$ & 8.0 & 10.58 & 16.7 & 49.55 & 626 & 93.2 \\
\hline $\mathrm{C} 1.1$ & 7.3 & 10.88 & 16.7 & 53.5 & 641 & 89.0 \\
\hline $\mathrm{C} 1.3$ & 6.1 & 7.77 & 13.3 & 38.2 & 356 & 90.5 \\
\hline $\mathrm{C} 1.4$ & 12.1 & 11.39 & 18.5 & 59.7 & 385 & 90.3 \\
\hline C1.5 & 5.9 & 12.19 & 19.0 & 62.2 & 472 & 92.4 \\
\hline \multicolumn{7}{|l|}{ Grupo Tratado } \\
\hline $\mathrm{T} 2.1$ & 9.7 & 11.28 & 18.1 & 56.5 & 410 & 92.1 \\
\hline $\mathrm{T} 2.2$ & 9.7 & 11.33 & 17.2 & 53.8 & 700 & 93.6 \\
\hline $\mathrm{T} 2.4$ & 11.3 & 12.2 & 17.4 & 57.1 & 1078 & 92.7 \\
\hline $\mathrm{T} 2.5$ & 9.0 & 11.25 & 17.7 & 55.5 & 419 & 93.6 \\
\hline $\mathrm{T} 3.1$ & 6.4 & 11.98 & 17.9 & 58.1 & 447 & 90.4 \\
\hline $\mathrm{T} 3.2$ & 7.3 & 12.09 & 18.7 & 58.3 & 779 & 91.4 \\
\hline T3.3 & 7.0 & 12.87 & 18.3 & 58.7 & 1193 & 87.3 \\
\hline
\end{tabular}

Fonte: Silva, ABA (2020). 
Tabela 4 - Avaliação do valor médio dos parâmetros clínicos e laboratoriais de camundongos Pepboy C57BL/6 CD45.1 receptores de células hematopoéticas de camundongos JAK2 ${ }^{\mathrm{WT} / \mathrm{Fl}}$-Vav/Cre CD45.2 na randomização entre grupos controles e tratados

\begin{tabular}{|c|c|c|c|}
\hline & Controle; $n=8$ & Fenformina; $n=8$ & $p^{*}$ \\
\hline Peso, g (DP) & $15,3(0,95)$ & $16,5(1,5)$ & 0.1282 \\
\hline Quimerismo, \% (DP) & $91,4(1,5)$ & $91,5(2,2)$ & 0.6807 \\
\hline Leucócitos, 10³/uL (DP) & $8,15(2,14)$ & $8,62(1,7)$ & 0.5530 \\
\hline Eritrócitos, $10^{6} / \mathrm{uL}$ (DP) & $10,9(1,53)$ & $11,85(0,6)$ & 0.2086 \\
\hline Hemoglobina, g/dL (DP) & $17,22(2)$ & $17,9(0,51)$ & 0.5944 \\
\hline Hematócrito, \% (DP) & $54,27(8,64)$ & $56,85(1,75)$ & 0.8048 \\
\hline Plaquetas, $10^{3} / \mathbf{u L}_{\text {(DP) }}$ & $503,7(109,3)$ & $718(320,6)$ & 0.2593 \\
\hline
\end{tabular}

Fonte: Silva, ABA (2020).

Após a randomização, os animais foram tratados com veículo (PBS; 100 $\mu \mathrm{L} / \mathrm{dia}$ ) ou fenformina $(40 \mathrm{mg} / \mathrm{kg} / \mathrm{dia}$ em $100 \mu \mathrm{L})$, ambos via intraperitoneal durante 4 semanas. A coleta do material para análise do hemograma foi realizada a cada 15 dias após o início do tratamento, nos dias D+15, D+30 e D+45. Os parâmetros hematimétricos avaliados (eritrócitos, hemoglobina, hematócrito, contagem de leucócitos e plaquetas) foram semelhantes entre os dois grupos, em todas as avaliações (Teste de Mann-Whitney, $p>0.05$ ) (Figura 8). Dessa forma, o tratamento com fenformina não modulou os parâmetros hematimétricos em modelo murino de NMP induzida por JAK $2^{\mathrm{V} 617 \mathrm{~F}}$. 
Figura 7 - Quimerismo dos camundongos receptores Pepboy C57BL/6 4 semanas após o TMO com células provenientes de camundongs JAK2 ${ }^{\mathrm{WT} / F 1-V a v / C r e}$
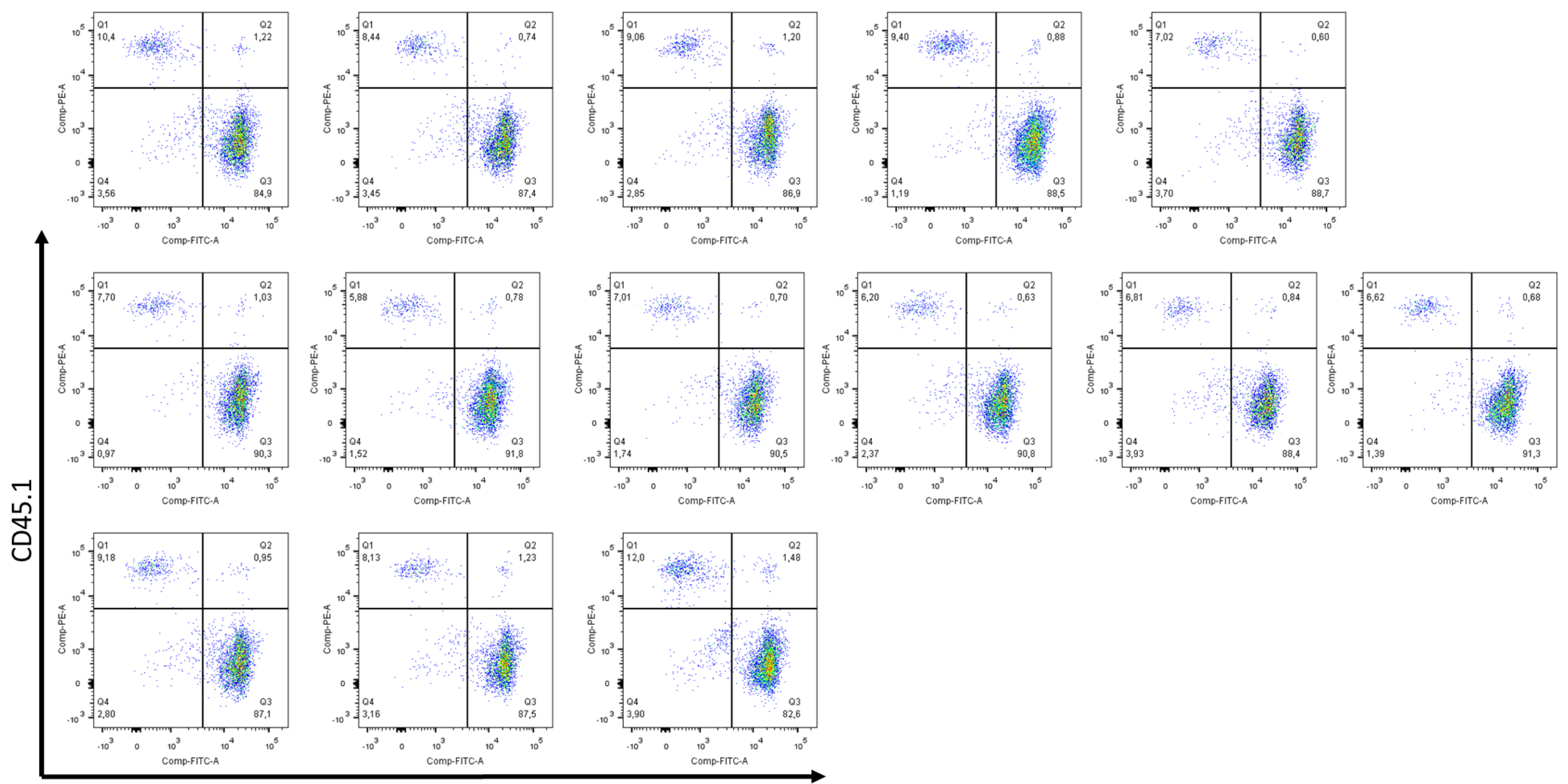

\section{CD45.2}

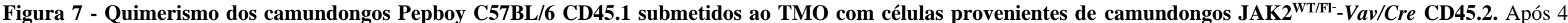
semanas do TMO, o quimerismo dos animais foi realizado em sangue periférico e a marcação foi realizada com os anticorpos PE-CD45.1 e FITC-CD45.2. O quadrante inferior direito representa as células do camundongo doador FITC-CD45.2. A aquisição foi feita no citômetro FACSCalibur (BD, Biosciences), e a análise no Programa FlowJo (TreestarINC). 
Figura 8 - Parâmetros hematimétricos dos camundongos Pepboy C57BL/6 transplantados com células provenientes dos camundongos $\mathrm{JAK2}^{\mathrm{WT} / \mathrm{Fl}-\mathrm{-}} \mathrm{Vav} / \mathrm{Cre}$ e tratados com fenformina ou veículo.
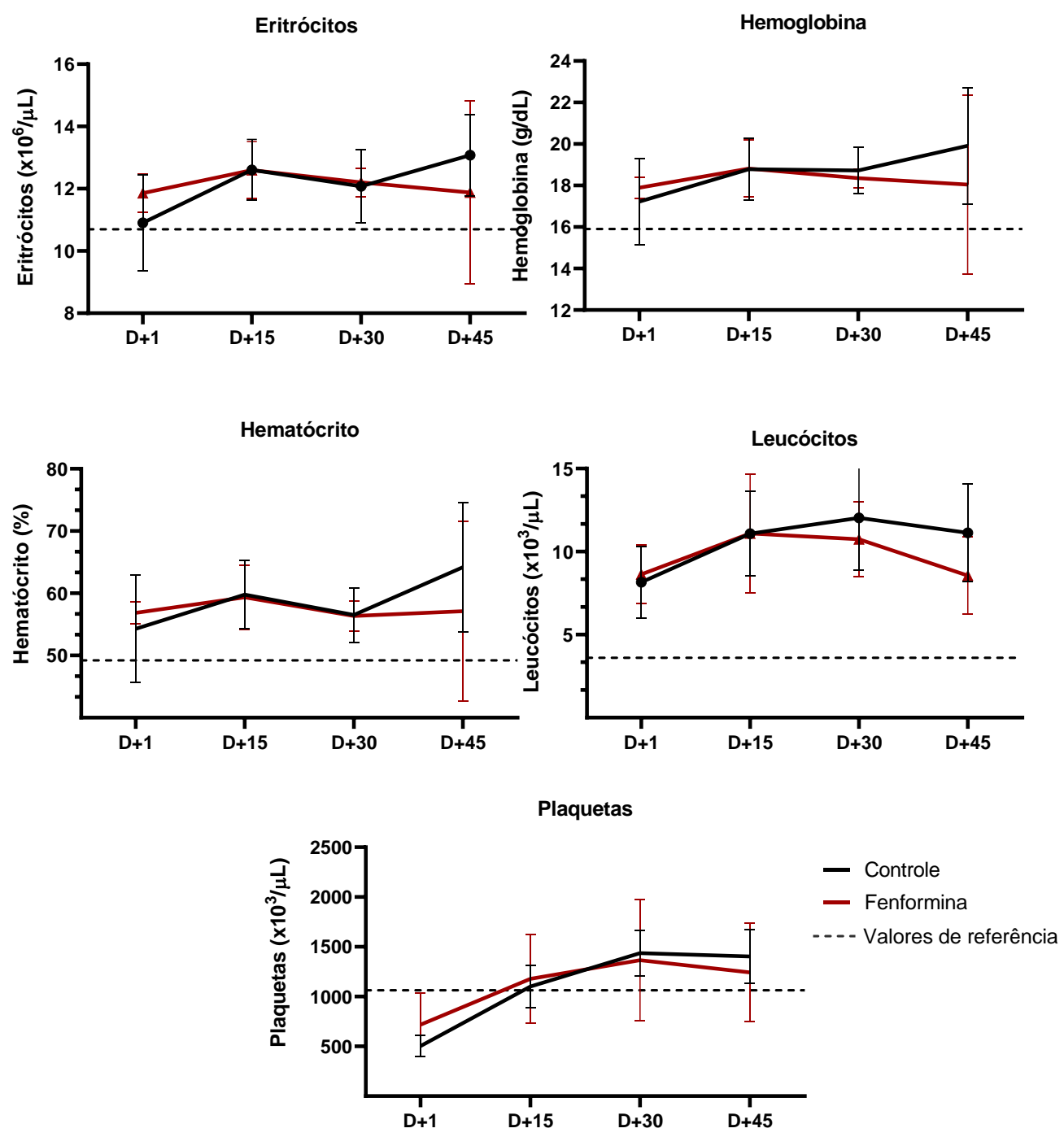

Dias de tratamento

Figura 8 - Fenformina in vivo não modulou parâmetros hematimétricos em modelo murino JAK2 ${ }^{\mathrm{V} 617 \mathrm{~F}}$. Parâmetros hematimétricos foram avaliados em modelo murino JAK2 ${ }^{\mathrm{V} 617 \mathrm{~F}}$ tratados in vivo com fenformina 40mg/kg/dia $(n=7)$ ou veículo (PBS; $100 \mu \mathrm{L} / \mathrm{dia})(\mathrm{n}=7)$ intraperitoneal durante 7 semanas. No eito Y estão os valores das unidades dos parâmetros hematimétricos avaliados, os valores de referência preconizados pelo The Jackson Laboratory são exibidos pelos pontos tracejados que partem da esquerda para direita no eixo Y. No eixo X estão os dias decorridos do tratamento com fenformina ou veículo. Não houve modulação nos parâmetros hematimétricos avaliados. Teste de Mann-Whitney, $p>0.05$.

Após 45 dias (aproximadamente 7 semanas) de tratamento com fenformina ou veículo, os camundongos foram eutanasiados e submetidos a avaliação do baço. Os achados encontrados no grupo controle e no grupo submetido ao tratamento com fenformina foram semelhantes quanto ao tamanho e peso do baço. Assim, a fenformina na dose administrada 
não foi capaz de modular o tamanho e o peso do baço dos animais quando comparado com o grupo controle ( $p>0.05$, teste de Mann-Whitney) (Figura 9).

Figura 9 - Peso e tamanho do baço dos animais Pepboy C57BL/6 CD45.1 transplantdos com células de animais JAK2 ${ }^{\mathrm{WT} / \mathrm{Fl}-}-$ Vav/Cre CD45.2 e tratados com fenformina ou veículo.

A

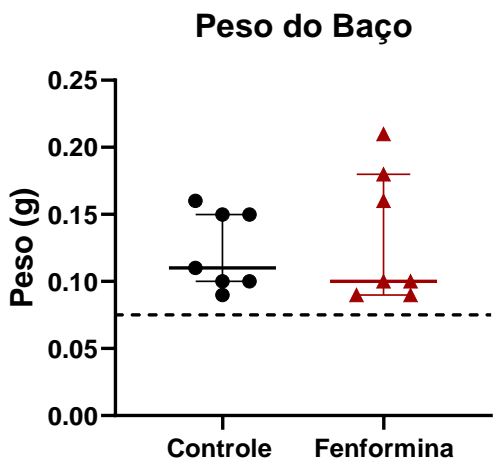

B

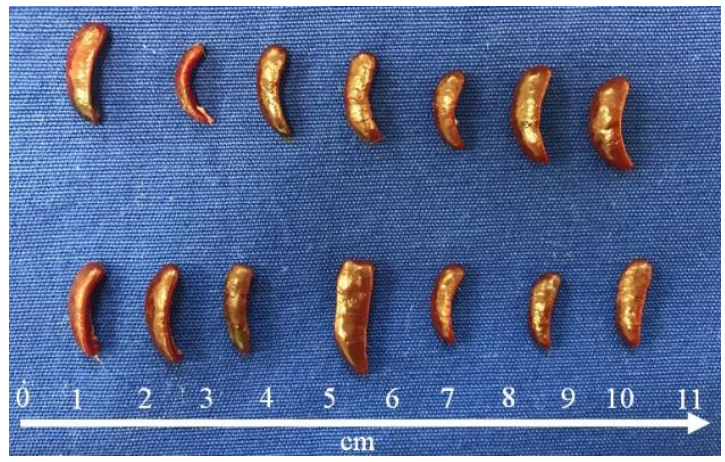

Figura 9 - Tratamento com fenformina não modula a esplenomegalia em modelo murino JAK2 ${ }^{\mathrm{V} 617 \mathrm{~F}}$. Modelo murino JAK2 ${ }^{\mathrm{V} 617 \mathrm{~F}}$ tratado in vivo com fenformina $40 \mathrm{mg} / \mathrm{kg} /$ dia ou veículo (PBS, $100 \mu \mathrm{L} /$ dia) intraperitoneal durante 7 semanas foram submetidos à eutanásia e avaliação do peso e tamanho do baço. Na figura à esquerda, o eixo $\mathrm{Y}$ indica o peso do baço dos animais em gramas, a linha horizontal representa a mediana com intervalo interquartil do peso do baço no grupo tratado com veículo $(\mathrm{n}=7)$ ou fenformina $(\mathrm{n}=7)$; Teste de Mann-Whitney, $p>0,05$. Valores de referência preconizados pelo The Jackson Laboratory são exibidos pelos pontos tracejados que partem do eixo Y. A figura à direita é a imagem do baço de animais tratados com veículo (alinhados na parte superior) ou fenformina (alinhados na parte inferior). O tratamento com fenformina, no regime utilizado, não foi capaz de modular a esplenomegalia apresentada pelos animais Pepboy C57BL/6 CD45.1 transplantados com células provenientes de camundongos JAK2 ${ }^{\mathrm{WT} / \mathrm{Fl}-}$ - $\mathrm{Vav} / \mathrm{Cre}$ CD45.2. Teste Mann-Whitney, $p>0.05$.

As células provenientes da MO total dos camundongos submetidos ao tratamento com fenformina (40 mg/kg/dia) ou veículo (PBS, $100 \mu \mathrm{L})$ via intraperitoneal durante 7 semanas foram cultivadas em metilcelulose (Methocult MethoCult ${ }^{\mathrm{TM}}$ GF M3534, StemCell, EUA) por 10 dias. A fenformina não modulou a capacidade clonogênica das células progenitoras hematopoéticas; o número de colônias e a capacidade de diferenciação de células progenitoras hematopoéticas foi semelhante entre o grupo tratado com fenformina e veículo (Teste Two-way ANOVA, $p>0.05$ ) (Figura 10). 
Figura 10 - $O$ tratamento com fenformina no regime utilizado não afetou a clonogenicidade das células da MO dos animais submetidos com TMO com células provenientes de camundongos JAK2 ${ }^{\mathrm{WT} / \mathrm{Fl}^{-}}-$Vav/Cre CD45.2
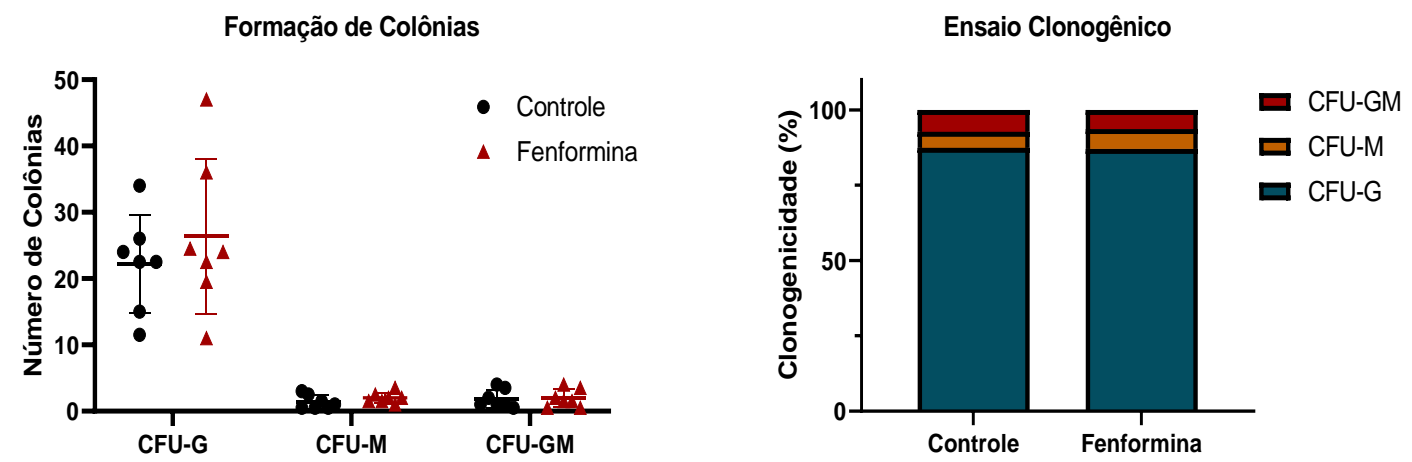

Figura 10 - A clonogenicidade das células da medula óssea dos animais tratados com fenformina e veículo foi semelhante. Os gráficos representam as colônias viáveis que foram cultivadas por 10 dias com células provenientes da MO de camundongos submetidos ao tratamento diário com fenformina $40 \mathrm{mg} / \mathrm{kg} / \mathrm{dia}$ IP ou veículo por 7 semanas. O número de colônias (eixo Y) e o tipo de colônia (eixo X) observada com base em sua morfologia estão ilustrados (painel esquerdo). O percentual de predominância de um determinado tipo morfológico de colônia em ambos os grupos experimentais (controle e tratados) são ilustrados (painel direito). As unidades formadoras de colônias são classificadas em: granulocítica (CFUG), macrofágicas (CFU-M), granulocítica-macrofágica (CFU-GM) e unidades formadoras de colônias eritroides (CFU-E). Não foi observada a formação de nenhuma colônia eritroide. Teste Two-way ANOVA, $p>0.05$.

A análise histológica do baço revelou presença de megacariócitos compatíveis com hematopoese extramedular e não houve diferença entre os grupos controle e tratados com fenformina. Na procura por ocorrência de fibrose foi utilizada a coloração pelo retículo. A celularidade da MO evidenciou a presença de granulócitos maduros, sem presença de fibrose e com aumento do número de megacariócitos, mas sem diferença entre controle e tratado, tanto na avaliação do baço (5.03 vs. $5.04, p=0.443)$ quanto na MO (9.85 vs. 8.14, $p=0.309)$ dos animais (Teste Mann-Whitney, $p>0.05$ ) (Tabela 5, Figura 11). 
Figura 11 - A contagem de megacariócitos não foi diferente no baço ou na medula óssea dos animais tratados com fenformina comparado ao grupo controle
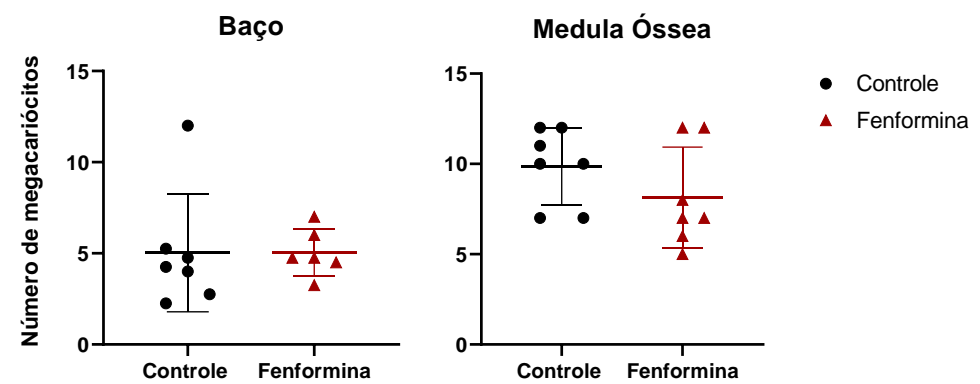

Figura 11 - Não houve diferença com relação a contagem de megacariócitos na histologia do baço ou da medula óssea dos animais tratados com fenformina ou veículo. O número de megacariócitos contados em 3 campos (eixo Y) na avaliação histológica dos grupos experimentais controle e fenformina são indicados. Não houve diferença no número de megacariócitos entre o grupo controle e grupo tratado. Teste de Mann-Whitney, $p>0.05$.

Tabela 5 - Avaliação histopatológica do baço e da MO dos animais Pepboy C57BL/6 transplantados com células de animais JAK2 ${ }^{\mathrm{WT} / \mathrm{FL}}-\mathrm{Vav} / \mathrm{Cre}$ CD45.2 e tratados com fenformina ou veículo

\begin{tabular}{lcc|cccc}
\hline \multicolumn{3}{c}{ Baço } & \multicolumn{4}{c}{ Medula Óssea } \\
C1.2 & Arquitetura & Megacariócitos & Celularidade & Granulócitos & Megacariócitos & Fibrose \\
C1.6 & Preservada & 2,25 & $100 \%$ & Maduros & 11 & Não \\
C1.7 & Preservada & 2,75 & $100 \%$ & Maduros & 7 & Não \\
C2.1 & Preservada & 12 & $100 \%$ & Maduros & 12 & Não \\
C2.3 & Preservada & 5 & $100 \%$ & Maduros & 7 & Não \\
C2.4 & Preservada & 4,75 & $100 \%$ & Maduros & 10 & Não \\
C2.5 & Preservada & 4,25 & $100 \%$ & Maduros & 10 & Não \\
T1.1 & Preservada & 4,75 & $100 \%$ & Maduros & 12 & Não \\
T1.2 & Preservada & 7 & $100 \%$ & Maduros & 6 & Não \\
T1.4 & NA & NA & $100 \%$ & Maduros & 7 & Não \\
T1.5 & Preservada & 4,75 & $100 \%$ & Maduros & 5 & Não \\
T2.1 & Preservada & 6 & $100 \%$ & Maduros & 8 & Não \\
T2.2 & Preservada & 4,5 & $100 \%$ & Maduros & 12 & Não \\
T2.3 & Preservada & 3,25 & $100 \%$ & Maduros & 12 & Não \\
\hline Fon & Silvada & $100 \%$ & Maduros & 7 & Não \\
\hline
\end{tabular}

Fonte: Silva, ABA. NA: não avaliado.

Quanto à quantificação e identificação das células-tronco progenitoras hematopoéticas (CTPH), o tratamento com fenformina, comparado ao controle, aumentou a frequência da população de células LSK (0.2608 vs. 0.3816, p=0.0023) ( $\left.\mathrm{Lin}^{-S} \mathrm{Sca}^{+}{ }^{+} \mathrm{c}-\mathrm{Kit}^{\mathrm{Hi}}\right)$, progenitores mieloides (MP) (1.505 vs. 2.159, $p=0.0070)\left(\mathrm{Lin}^{-} \mathrm{Sca}{ }^{-} \mathrm{c}-\mathrm{Kit}^{\mathrm{Hi}}\right)$ e progenitores multipotentes ( 0.1265 vs. $0.2479, p=0.006)\left(\mathrm{MPP}: \mathrm{Lin}^{-} \mathrm{Sca}^{+} \mathrm{c}-\mathrm{Kit}^{+} \mathrm{CD} 48^{+} \mathrm{CD} 150^{-}\right.$) na $\mathrm{MO}$ total de camundongos receptores Pepboy C57BL/6 CD45.1 que receberam o transplante de camundongos JAK2 ${ }^{\mathrm{WT} / \mathrm{Fl}}$-Vav/Cre CD45.2 (Teste Mann-Whitney, $p<0.05$ ) (Figura 12). 
Figura 12 - $O$ tratamento com fenformina aumentou a frequência das células tronco hematopoéticas (CTH) na MO dos animais receptores submetidos ao TMO

Frequência de LT-HSC

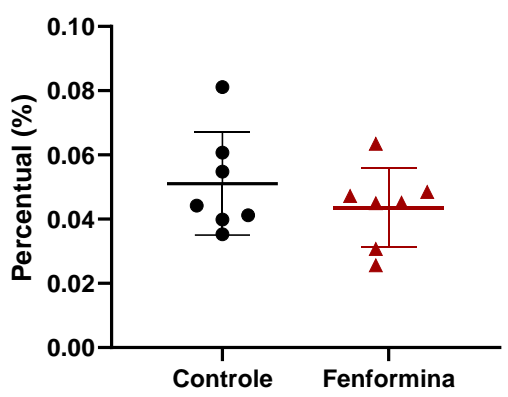

Frequência de Progenitores Multipotentes

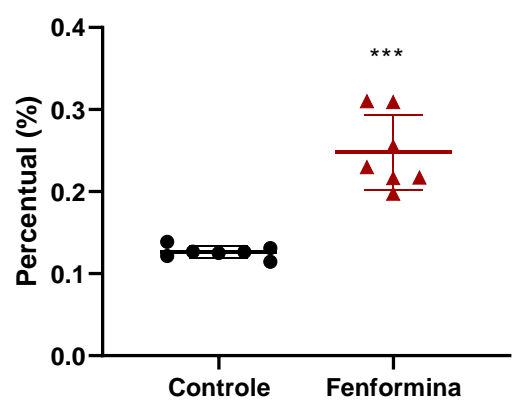

Frequência de ST-HSC

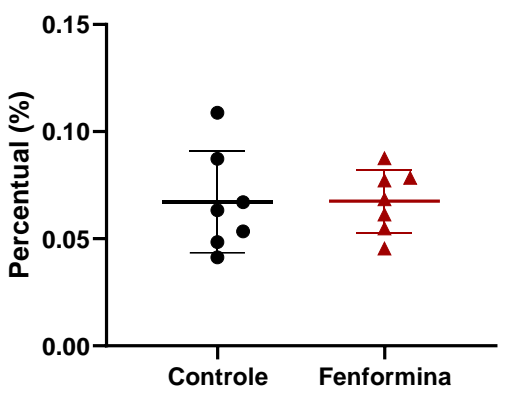

Frequência de LSK

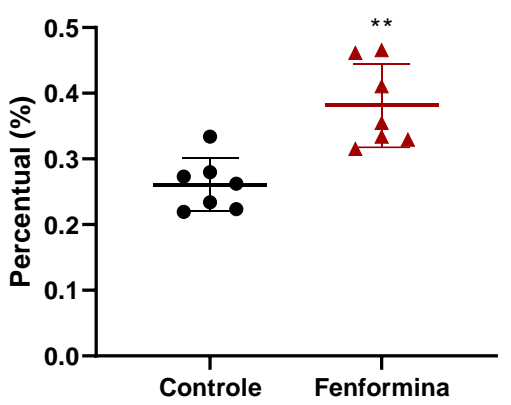

Frequência de Progenitores Mielóide

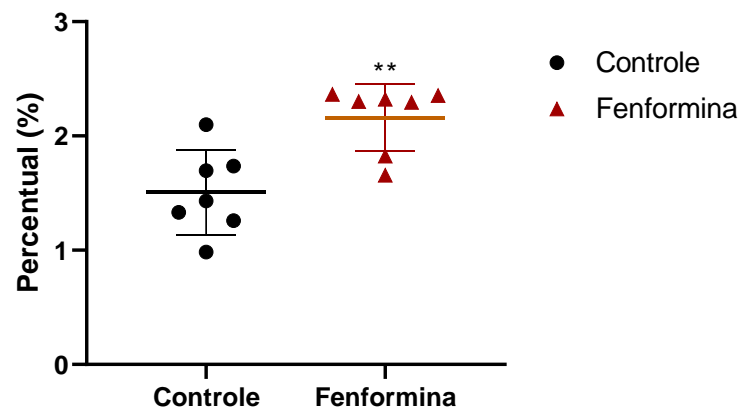

Figura 12 - Fenformina aumentou a frequência da população LSK, MPP e MP na medula óssea dos animais. A identificação da frequência de células-tronco hematopoéticas (CTH) foi realizada por citometria de fluxo por meio da marcação com anticorpos Sca-1, CD117 (c-kit), CD48 e CD150. O percentual da população de células avaliadas na medula óssea dos animais submetidos ao tratamento está indicado no eixo $\mathrm{Y}$, os grupos experimentais que receberam tratamento diário com fenformina $40 \mathrm{mg} / \mathrm{kg} / \mathrm{dia}$ IP ou veículo (PBS, $100 \mu \mathrm{L}$ ) estão indicados no eixo $\mathrm{X}$. As linhas horizontais representam a média com desvio padrão de cada grupo avaliado. Os valores de $p$ são apresentados como ** $p<0.01$; *** $p<0.001$. Teste de Mann-Whitney.

A avaliação dos precursores eritroides no baço e na $\mathrm{MO}$ dos animais tratados com fenformina ou veículo, por de citometria de fluxo demonstrou que ao percentual de 
eritroblastos ortocromáticos $\left(\mathrm{CD} 71^{+}\right.$Ter $\left.119^{+} \mathrm{FSC}^{+}\right)$, reticulócitos $\left(\mathrm{CD} 71^{+}\right.$Ter $\left.119^{+} \mathrm{FSC}^{-}\right) \mathrm{e}$ eritrócitos (CD71-Ter119+5SC-) em ambos os grupos foi semelhante (Teste Mann-Whitney, $p>0.05)$ (Figura 13).

Figura 13 - População de precursores eritroides no baço e na medula óssea dos animais tratados com fenformina não são diferentes em relação ao grupo tratado com veículo

Baço

Eritroblastos Ortocromáticos

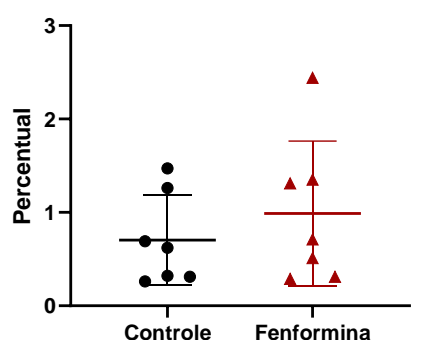

Eritroblastos Ortocromáticos

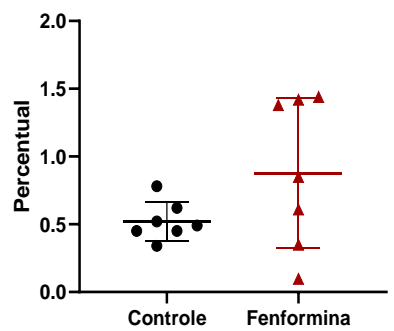

Reticulócitos

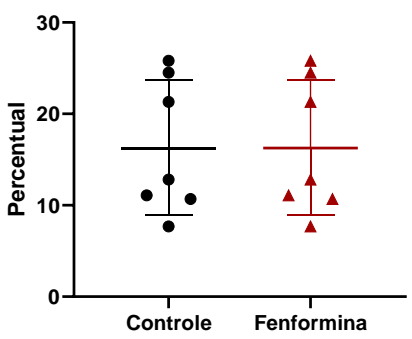

Medula óssea

Reticulócitos

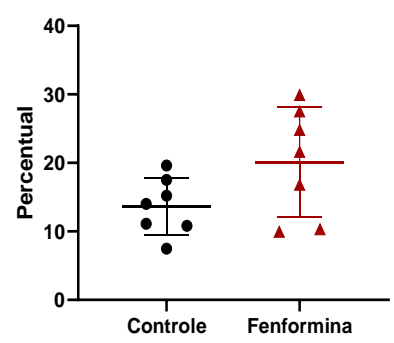

Eritrócitos

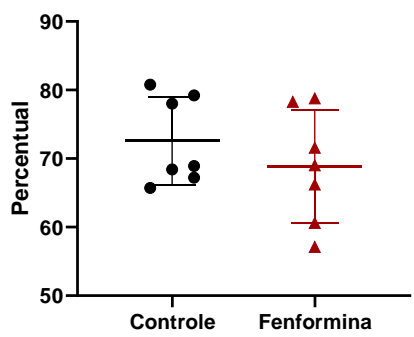

Eritrócitos

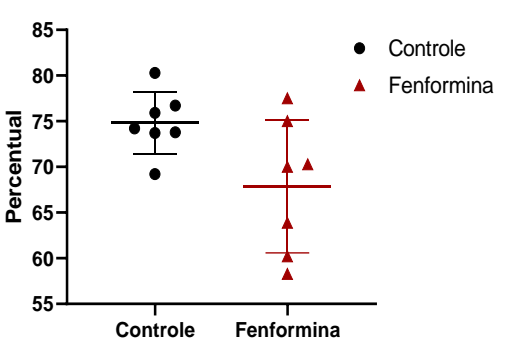

Figura 13 - Não houve diferença no percentual de precursores eritroides no baço ou na medula óssea em ambos os grupos, fenformina $40 \mathrm{mg} / \mathrm{kg} / \mathrm{dia}$ IP ou veículo (PBS, 100 $\mu \mathrm{L}$ ). Os precursores eritroides foram avaliados por citometria de fluxo pela marcação das células provenientes do baço ou da medula óssea (MO) com os anticorpos CD71 e Ter119. Cada gráfico apresenta no eixo Y o percentual de cada população de precursores eritroides no baço ou na $\mathrm{MO}$ dos camundongos. O eixo $\mathrm{X}$ representa os dados referentes aos grupos controle e tradados. Não houve diferença na população de precursores eritroides em ambos os grupos avaliados, tanto no baço quanto na MO provenientes dos animais submetidos ao transplante de medula óssea e tratados ou não diariamente com fenformina $40 \mathrm{mg} / \mathrm{kg} /$ dia IP durante 7 semanas. Os gráficos apresentam os valores das médias com desvio-padrão. Teste de Mann-Whitney, $p>0,05$.

4.3 O tratamento ex vivo com fenformina não modula a capacidade de autorrenovação e diferenciação de células-tronco e progenitoras hematopoéticas em modelo murino de NMP induzida por JAK2 ${ }^{\mathrm{V} 617 \mathrm{~F}}$

No dia do TMO, os animais foram pareados pelo peso e separados em grupos, cada grupo foi transplantado com células expostas ao veículo $(n=6)$, metformina $(n=6)$ ou 
fenformina $(n=6)$. Os grupos experimentais eram similares quanto ao peso e parâmetros hematimétricos $(p>0.05)$ (Tabela 6).

Tabela 6. Peso médio dos animais no dia do TMO para separação em grupos que receberiam as

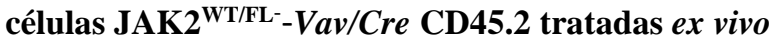

\begin{tabular}{ccccc}
\hline & Controle & Fenformina & Metformina & p valor \\
Peso, g; média (DP) & $19,36(2,1)$ & $21,29(1,1)$ & $20,26(1,6)$ & 0.1738 \\
\hline
\end{tabular}

Fonte: Silva, ABA (2020)

Após o TMO com as células tratadas ex vivo, os animais receptores Pepboy C57BL/6 CD45.1 foram avaliados quanto ao quimerismo e parâmetros hematimétricos a cada 15 dias no primeiro mês e a cada 4 semanas do segundo ao quarto mês. A metformina reduziu o quimerismo, comparado ao controle, na semana 4 de tratamento $(4,5 \% \mathrm{x} 1,2 \%$, respectivamente, $p<0,05)$. A fenformina não reduziu o quimerismo em nenhum dos momentos testados durante o seguimento dos animais. Após 4 meses de seguimento, não houve diferença entre o quimerismo e os parâmetros hematimétricos dos animais tratados com veículo (PBS), metformina ou fenformina (Figura 14). 
Figura 14 - Quimerismo e parâmetros hematimétricos dos camundongos Pepboy C57BL/6 CD45.1 submetidos ao TMO com células provenientes de camundongos JAK2 ${ }^{\mathrm{WTFL}}-\mathrm{Vav} / \mathrm{Cre}$ CD45.2 submetidas ao tratamento ex vivo com fenformina, metformina ou veículo

Quimerismo

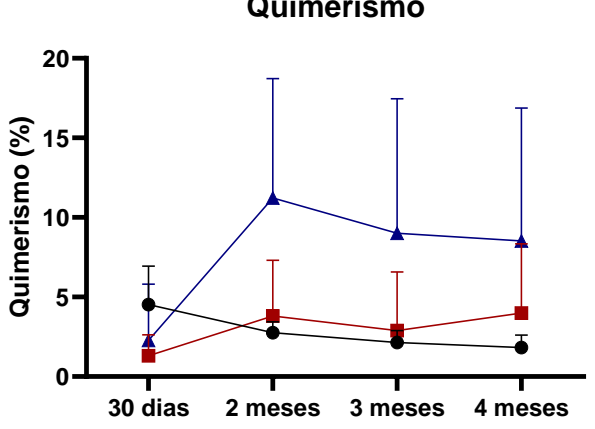

Hematócrito

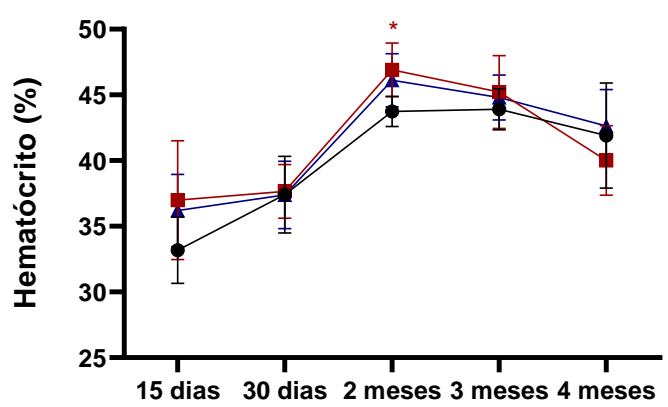

Leucócitos

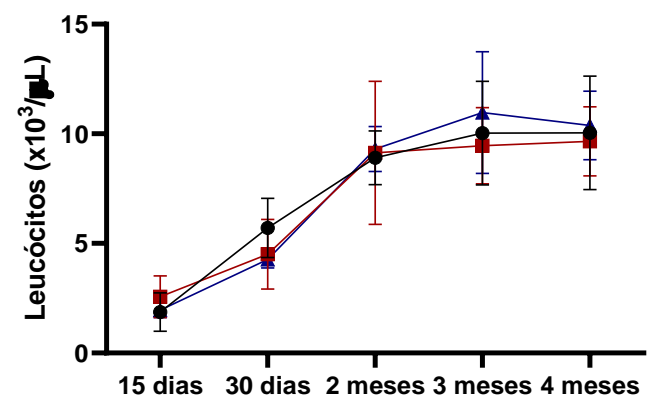

Eritrócitos

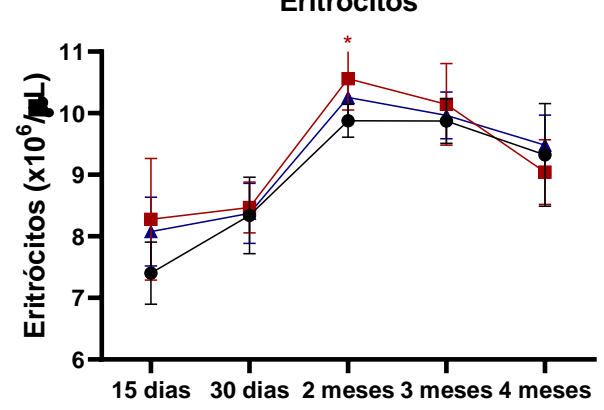

Plaquetas

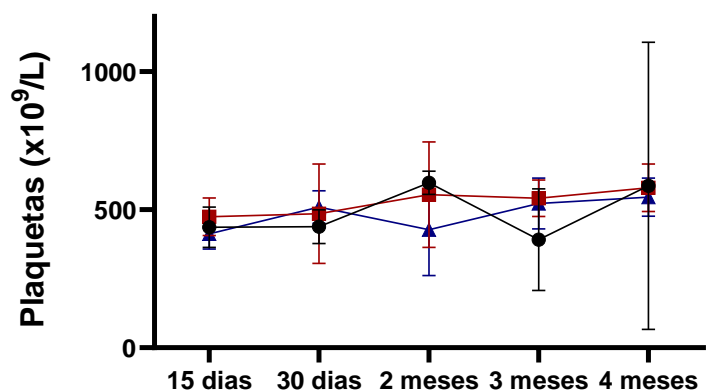

Hemoglobina

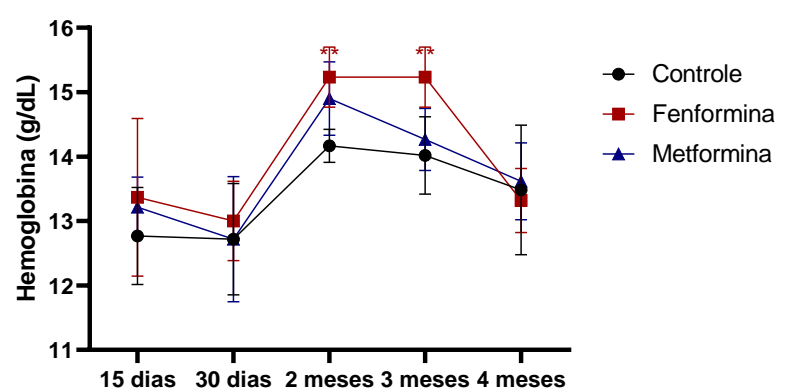

Figura 14 - Após 16 semanas de seguimento, o quimerismo e os parâmetros hematimétricos não diferiram entre os grupos de animais transplantados com

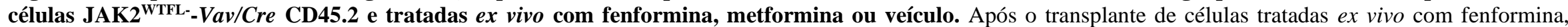
metformina ou veículo em animais receptores Pepboy C57BL/6 CD45.1, os animais receptores foram acompanhados durante 16 semanas e avaliados quanto ao quimerismo e parâmetros hematimétricos. No eixo Y de cada gráfico encontra-se o quimerismo e os parâmetro hematimétricos avaliados e no eito X o tempo de acompanhamento dos animais. O quimerismo foi avaliado por citometria de fluxo pela marcação das células do sangue periférico dos animais com os anticorpos PECD45.1 e FITC-CD45.2. Os gráficos apresentam os valores das médias com desvio-padrão e os valores de $p$ são apresentados como * $p<0.05$; ** $p<0.01$. Teste $O n e-W a y$ ANOVA, 
4.4 Fenformina inibe a capacidade de formação de colônia de células primárias de paciente $\mathrm{JAK} 2^{\mathrm{V} 617 \mathrm{~F}}$

O ensaio de formação de colônias foi realizado em meio semissólido de metilcelulose (MethoCult H4330; StemCell Technologies Inc., Canada) com células provenientes de paciente JAK2 ${ }^{\mathrm{V} 617 \mathrm{~F}}$ diagnosticado com MF pós-PV. Foram utilizadas as concentrações de $1 \mathrm{mM}$ e $2 \mathrm{mM}$ de fenformina e PBS como controle. Após 14 dias de cultivo, observou-se que o tratamento com fenformina aboliu a formação de colônias (Figura 15).

Figura 15 - Ensaio de formação espontânea de colônias com células provenientes de paciente diagnosticado com mielofibrose $\mathrm{JAK}^{\mathrm{V} 617 \mathrm{~F}}$

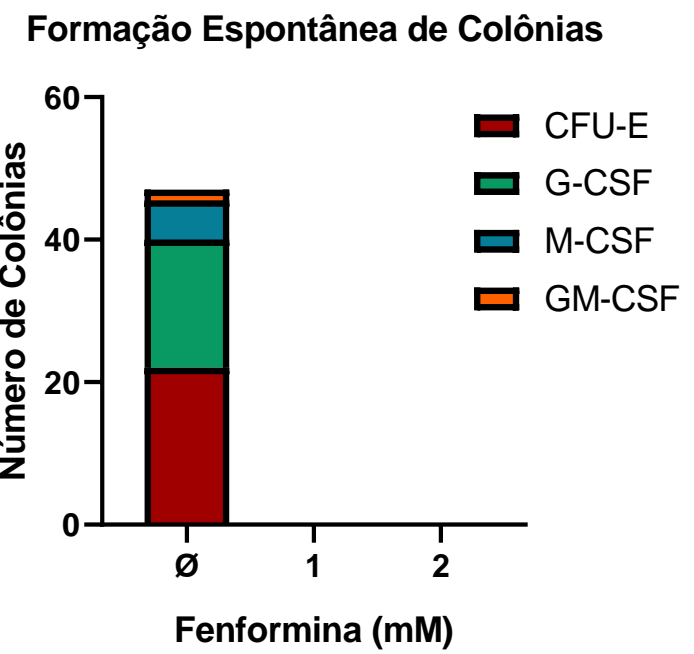

Figura 15 - A fenformina inibe a formação de colônias em células primárias JAK ${ }^{\mathrm{V} 617 \mathrm{~F}}$. As células provenientes de paciente com JAK2 ${ }^{\mathrm{V} 617 \mathrm{~F}}$ foram cultivadas por 14 dias na ausência ou presença de fenformina em diferentes concentrações ( $1 \mathrm{~mm}$ ou $2 \mathrm{mM})$ em estufa com $\mathrm{CO}_{2} . \mathrm{O}$ gráfico representa no eixo $\mathrm{Y}$ o número de colônias identificadas no experimento e no eixo $X$ a concentração de fenformina utilizada. A barra representa a quantidade de cada tipo morfológico de colônia identificada. Fenformina a partir de $1 \mathrm{mM}$ aboliu a clonogenicidade das células. 


\section{Discussão}

Neste trabalho realizamos uma investigação dos efeitos antineoplásicos da fenformina em modelo murino de NMP com a mutação JAK2 ${ }^{\mathrm{V} 617 \mathrm{~F}}$. Nossos resultados demonstraram que a fenformina em modelos in vitro foi capaz de reduzir a viabilidade celular e aumentar o percentual de células apoptóticas. No modelo murino de NMP $\mathrm{JAK} 2^{\mathrm{V} 617 \mathrm{~F}}$, fenformina in vivo aumentou a frequência das populações LSK, MPP e MP, porém não alterou os precursores eritroides no baço e na $\mathrm{MO}$, as contagens hematimétricas no sangue periférico, a esplenomegalia, a capacidade clonogênica e o aspecto morfológico da MO e do baço.

O presente trabalho surgiu a partir de resultados anteriormente descritos por nosso grupo de pesquisa em que a metformina exerce efeito antineoplásico e reduz sintomas clínicos em modelo murino de NMP com fenótipo de PV. Assim, avaliamos o efeito antineoplásico da biguanida fenformina em modelo de NMP JAK2 ${ }^{\mathrm{V} 617 \mathrm{~F}}$, cujos resultados poderiam indicar um reposicionamento do fármaco.

Nas células SET-2 com a mutação JAK2 ${ }^{\mathrm{V} 617 \mathrm{~F}}$ observamos que a fenformina foi capaz de exercer efeito citostático a partir dos ensaios de viabilidade e apoptose celular. Efeitos similares de redução de viabilidade celular foram encontrados por Malek e colaboradores $(2015)^{65}$ em modelo de mieloma múltiplo. Uma das limitações do nosso estudo in vitro é a ausência de ensaios de proliferação celular para que pudéssemos investigar o potencial citotóxico da fenformina. Análise do ciclo celular, da ativação das vias de morte celular e ação da fenformina na mitocôndria são ensaios que seriam de grande importância para melhor compreensão, principalmente no que se refere à investigação do mecanismo de ação da fenformina na inibição do complexo I na mitocôndria, conforme descrito em outros $\operatorname{modelos}^{52,71}$.

$\mathrm{O}$ estabelecimento e a padronização do modelo murino de NMP JAK2 ${ }^{\mathrm{V} 617 \mathrm{~F}}$ foi

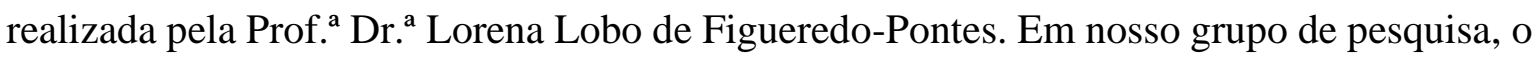
uso do modelo murino foi primeiramente utilizado pelo prof. Dr. João Agostinho MachadoNeto e consolidada no presente trabalho. Uma das dificuldades encontradas durante a consolidação do modelo foi a etapa de irradiação dos animais. Atualmente, nosso centro de pesquisa encontra-se sem o equipamento para realizar a irradiação. Os animais são irradiados em outro centro de pesquisa, a viagem expõe os animais a um estresse adicional, o que pode prejudicar o procedimento de TMO. A etapa de irradiação é fundamental para o sucesso do 
TMO, pois causa mieloablação e aumenta a chance de haver enxertia das células transplantadas. A quantidade de células transplantadas também é de fundamental importância para o sucesso do TMO. Em nosso protocolo, $5 \times 10^{6}$ células provenientes da MO total foram transplantadas nos camundongos receptores. Andrade e colaboradores $(2011)^{83}$ demonstraram que $1 \times 10^{6}$ são suficientes para garantir a enxertia do transplante, porém seu protocolo difere do nosso em dois aspectos (dose e local de irradiação e via de inoculação das células). No protocolo de Andrade e colaboradores $(2011)^{83}$, os animais foram irradiados subletalmente, com apenas uma dose de $2.7 \mathrm{~Gy}$, que foi aplicada no corpo todo dos animais ou apenas na tíbia/fêmur; as células foram inoculadas por via intravenosa ou intracaudal. No nosso protocolo, os animais foram irradiados letalmente 7Gy no corpo todo, e as células foram inoculadas via plexo retro-ocular.

Uma alternativa para aperfeiçoarmos nosso modelo murino é fazer a seleção das células LSK e transplantá-las no camundongo receptor. No protocolo estabelecido por nosso grupo, a MO total do camundongo doador, e não apenas $\mathrm{CTH}$, foi transplantada no camundongo receptor. A população LSK consiste em células mais imaturas e que são responsáveis pelo repovoamento da $\mathrm{MO}^{84}$. É de grande interesse a melhor compreensão da atividade das CTH, para isso, é importante que façamos a purificação das CTH e realizemos ensaios a partir somente das células selecionadas, isto é, LT-HSC, ST-HSC e MPP, conforme descrito e sugerido em estudos de $\mathrm{CTH}^{84-86}$.

No regime de tratamento adotado, a fenformina $40 \mathrm{mg} / \mathrm{kg} / \mathrm{dia}$ via IP durante 7 semanas não foi capaz de modular os índices hematimétricos e os sintomas clínicos apresentados pelo modelo murino de NMP JAK2 ${ }^{\mathrm{V} 617 \mathrm{~F}}$ com fenótipo de PV. A presença de esplenomegalia, contagem de eritrócitos, hemoglobina e hematócrito similar entre os dois grupos indicam que a fenformina não modula o fenótipo apresentado pelos animais. Diferente do tratamento com fenformina, a biguanida metformina demonstrou vantagem terapêutica ao reduzir a esplenomegalia, contagem de plaquetas e alterar a arquitetura do baço no modelo murino de NMP JAK2 ${ }^{\mathrm{V} 617 \mathrm{~F}}$, embora não module a contagem de eritrócitos, hematócrito e hemoglobina ${ }^{73,87}$.

O aumento da frequência de progenitores multipotentes, progenitores mieloides e da população LSK nos animais tratados com fenformina é um resultado que merece ser aprofundado. É interessante pontuar que o aumento de CTH não foi capaz de refletir no aumento das populações de células sanguíneas maduras que podem ser identificadas no SP, não houve diferença entre os dois grupos analisados. Uma possível justificativa para a 
ausência de reflexo do aumento das CTH no SP é o tempo de tratamento e o tempo de acompanhamento dos animais. É possível que o tratamento por 7 semanas não seja suficiente para impactar as células sanguíneas do SP.

Em camundongos irradiados e transplantados com CTH, as ST-HSC e os MPP são responsáveis pela reconstituição da hematopoese transitoriamente durante as 6 primeiras semanas pós-transplante, após isso perdem sua capacidade de autorrenovação e diferenciamse dando origem aos progenitores oligopotentes linfo-mieloide e eritroides. Enquanto isso, ocorre o estabelecimento das LT-HSC na MO e o início do reestabelecimento da hematopoese ${ }^{80,88-91}$. As células progenitoras mais imaturas estão incluídas dentro da população LSK $^{90,91}$. O aumento de LSK observado nos animais tratados com fenformina pode ser decorrente do aumento da MPP. A fenformina também aumentou os MP. A ausência de efeitos do tratamento com fenformina sob as células progenitoras eritroides no baço e na $\mathrm{MO}$ e na capacidade clonogênica dos animais nos indica que a fenformina não afeta o processo de maturação das células e não modula a eritropoese. A inclusão da avaliação dos progenitores mieloides (progenitor comum mieloide, progenitor mieloeritroide, progenitor granulomonocítico) poderia contribuir para o refinamento da avaliação da hematopoese. Entretanto, diante dos resultados negativos obtidos até o momento, não prosseguimos com as investigações.

Nossa limitação na avaliação das vias de ativação JAK/STAT deram-se às dificuldades encontradas no processo de extração das proteínas. O material biológico extraído do baço e da MO dos animais no final do tratamento não resultou em quantidade suficiente de proteína para avaliação de proteínas das vias JAK/STAT, AKT e mTOR. Com relação a investigação do desenvolvimento de acidose láctica ou lesão hepática nos animais, a quantidade limitada de sangue que poderíamos obter de cada animal nos fez priorizar a execução da análise do hemograma e avaliação das CTH por meio da citometria de fluxo.

Para responder se o tratamento com fenformina afetaria a capacidade de enxertia e autorrenovação das CTH, executamos um tratamento ex vivo da MO de animais JAK2 ${ }^{\text {WT/Fl- }}$ -Vav/Cre CD45.2 com veículo (PBS), fenformina ou metformina. O grupo com metformina foi adicionado com base nos resultados já publicados por nosso grupo acerca dos efeitos da metformina em NMP. Após 4 semanas do transplante de MO com células tratadas ex vivo, os animais transplantados com células da MO tratadas com veículo, fenformina ou metformina apresentaram enxertia de células JAK2 ${ }^{\text {WT/Fl- }}$-Vav/Cre CD45.2 provenientes dos camundongos doadores, mas não apresentaram fenótipo de NMP. Vale ressaltar que este 
modelo avalia a CTH e não se espera desenvolvimento de fenótipo de NMP. Na 4a semana, observamos baixa frequência de células $\mathrm{JAK} 2^{\mathrm{WT} / \mathrm{Fl}}$-Vav/Cre CD45.2 no grupo de animais que recebeu células da MO tratadas ex vivo com metformina, o que sugere que a metformina possa ter efeito na CTH. Entretanto, na semana 16 de seguimento, os animais dos 3 grupos não diferiram quanto a percentagem de quimerismo e parâmetros hematimétricos. Trabalho recente do nosso grupo de pesquisa, refinou a avaliação do efeito da metformina na CTH em modelo murino de NMP e evidenciou que a metformina não compromete a função de CTH a longo prazo $^{87}$. O TMO com células tratadas ex vivo é um procedimento informativo acerca da capacidade de autorrenovação da CTH. O modelo de tratamento ex vivo seguido de TMO poderia ser refinado a partir do isolamento e cultivo de células progenitoras $\left(\mathrm{CD} 117^{+}\right) \mathrm{a}$ serem transplantadas.

O ensaio de clonogenicidade utilizando células primárias provenientes de paciente JAK2 ${ }^{\mathrm{V} 617 \mathrm{~F}}$ com MF pós-PV tratadas com fenformina evidenciou o efeito da droga na CTH in vitro. Entretanto, a ação da fenformina na capacidade clonogênica não foi observado no tratamento in vivo. Tal fato pode ser justificado pela dose insuficiente utilizada no tratamento in vivo. Testamos o potencial antineoplásico da fenformina na dose de $100 \mathrm{mg} / \mathrm{kg} / \mathrm{dia}$ via IP em modelo murino JAK $2^{\mathrm{V} 617 \mathrm{~F}}$. Porém, o tratamento apresentou alta toxicidade ${ }^{92} \mathrm{e}$ os animais não sobreviveram ou tiveram que ser eutanasiados por toxicidade 7 dias após o início do tratamento.

Os efeitos antineoplásicos da fenformina observados nos ensaios in vitro não foram reproduzidos nos ensaios in vivo. Os resultados não evidenciaram quaisquer efeitos da fenformina in vivo, em doses toleradas, em modelo murino JAK2 ${ }^{\mathrm{V} 617 \mathrm{~F}}$. 
CONCLUSÕES 


\section{Conclusões}

1. Em células SET-2 JAK2 ${ }^{\mathrm{V} 617 \mathrm{~F}}$, o tratamento com a biguanida fenformina reduz a viabilidade celular e aumenta o percentual de células apoptóticas.

2. Em modelo murino de NMP JAK2 $2^{\mathrm{V} 617 \mathrm{~F}}$, o tratamento in vivo com fenformina $40 \mathrm{mg} / \mathrm{kg} /$ dia via IP durante 7 semanas, comparado ao grupo tratado com veículo, não apresentou diferença na modulação dos índices hematimétricos, esplenomegalia, histologia do baço e MO, percentual de progenitores eritroides no baço e na MO, capacidade clonogênica de células da MO.

3. Em modelo murino de NMP JAK2 $2^{\mathrm{V} 617 \mathrm{~F}}$, o tratamento in vivo com fenformina $40 \mathrm{mg} / \mathrm{kg} / \mathrm{dia}$ via IP durante 7 semanas, comparado ao grupo tratado com veículo, aumentou a frequência das CTH LSK, MPP e MP.

4. Animais transplantados com células de $\mathrm{MO} \mathrm{JAK} 2^{\mathrm{V} 617 \mathrm{~F}}$ tratadas ex vivo com veículo, fenformina ou metformina apresentaram enxertia de células $\mathrm{JAK} 2^{\mathrm{WT} / \mathrm{Fl}}-\mathrm{Vav} / \mathrm{Cre}$ CD45.2 provenientes dos camundongos doadores. Na semana 16 de seguimento, os animais dos 3 grupos não diferiram quanto a percentagem de quimerismo e parâmetros hematimétricos. Portanto, o tratamento ex vivo com fenformina não modulou a autorrenovação da CTH de célula JAK2 $2^{\mathrm{V} 617 \mathrm{~F}}$.

5. Fenformina $1 \mathrm{mM}$ e $2 \mathrm{mM}$ por 14 dias, in vitro, aboliu a formação de colônias de células primárias $\mathrm{JAK} 2^{\mathrm{V} 617 \mathrm{~F}}$. 


\section{REFERÊNCIAS}

1. Swerdlow, S. H. et al. WHO Classification of Tumors of Haematopoietic and Lymphoid Tissues. (2017).

2. DAMESHEK, W. Some speculations on the myeloproliferative syndromes. Blood 6, 372-5 (1951).

3. Barbui, T. The leukemia controversy in myeloproliferative disorders: Is it a natural progression of disease, a secondary sequela of therapy, or a combination of both? Semin. Hematol. 41, 15-17 (2004).

4. Arber, D. A. et al. The 2016 revision to the World Health Organization classification of myeloid neoplasms and acute leukemia. Blood 127, 2391-2405 (2016).

5. Lanikova, L., Babosova, O. \& Prchal, J. T. Experimental Modeling of Myeloproliferative Neoplasms. Genes (Basel). 10, 813 (2019).

6. Baxter, E. J. et al. Acquired mutation of the tyrosine kinase JAK2 in human myeloproliferative disorders. Lancet 365, 1054-1061 (2005).

7. Grinfeld, J., Nangalia, J. \& Green, A. R. Molecular determinants of pathogenesis and clinical phenotype in myeloproliferative neoplasms. Haematologica 102, 7-17 (2017).

8. Spivak, J. L. How I treat polycythemia vera. Blood 134, 341-352 (2019).

9. Zimran, E., Hoffman, R. \& Kremyanskaya, M. Current approaches to challenging scenarios in myeloproliferative neoplasms. Expert Rev. Anticancer Ther. 18, 567-578 (2018).

10. Tefferi, A. \& Pardanani, A. Essential Thrombocythemia. N. Engl. J. Med. 381, 2135-2144 (2019).

11. Tefferi, A., Vannucchi, A. M. \& Barbui, T. Essential thrombocythemia treatment algorithm 2018. Blood Cancer J. 8, 2 (2018).

12. Kralovics, R. et al. A Gain-of-Function Mutation of JAK2 in Myeloproliferative Disorders. N. Engl. J. Med. 352, 1779-1790 (2005).

13. Levine, R. L. et al. Activating mutation in the tyrosine kinase JAK2 in polycythemia vera, essential thrombocythemia, and myeloid metaplasia with myelofibrosis. Cancer Cell 7, 387-397 (2005).

14. Kleppe, M. et al. Dual Targeting of Oncogenic Activation and Inflammatory Signaling Increases Therapeutic Efficacy in Myeloproliferative Neoplasms. Cancer Cell 33, 29-43.e7 (2018).

15. Szuber, N. \& Tefferi, A. Driver mutations in primary myelofibrosis and their implications. Curr. Opin. Hematol. 25, 129-135 (2018).

16. James, C. et al. A unique clonal JAK2 mutation leading to constitutive signalling causes polycythaemia vera. Nature 434, 1144-1148 (2005).

17. Tefferi, A. et al. Targeted deep sequencing in polycythemia vera and essential thrombocythemia. Blood Adv. 1, 21-30 (2016).

18. Vannucchi, A. M., Guglielmelli, P. \& Tefferi, A. Polycythemia vera and essential thrombocythemia. Curr. Opin. Hematol. 25, 112-119 (2018).

19. Tefferi, A. et al. CALR vs JAK2 vs MPL-mutated or triple-negative myelofibrosis: clinical, cytogenetic and molecular comparisons. Leukemia 28, 1472-1477 (2014).

20. Rumi, E. \& Cazzola, M. Diagnosis, risk stratification, and response evaluation in classical myeloproliferative neoplasms. Blood 129, 680-692 (2017).

21. Hobbs, G. S., Rozelle, S. \& Mullally, A. The Development and Use of Janus Kinase 2 Inhibitors for the Treatment of Myeloproliferative Neoplasms. Hematol. Oncol. Clin. North Am. 31, 613-626 (2017).

22. Mascarenhas, J. O., Cross, N. C. P. \& Mesa, R. A. The future of JAK inhibition in myelofibrosis and beyond. Blood Rev. 28, 189-196 (2014).

23. Hubbard, S. R. Mechanistic Insights into Regulation of JAK2 Tyrosine Kinase. Front. Endocrinol. 
(Lausanne). 8, 361 (2018).

24. Vardiman, J. W. et al. The 2008 revision of the World Health Organization (WHO) classification of myeloid neoplasms and acute leukemia: rationale and important changes. Blood 114, 937-951 (2009).

25. Staerk, J. \& Constantinescu, S. N. The JAK-STAT pathway and hematopoietic stem cells from the JAK2 V617F perspective. JAK-STAT 1, 184-190 (2012).

26. Scott, L. M. et al. JAK2 Exon 12 Mutations in Polycythemia Vera and Idiopathic Erythrocytosis. $N$. Engl. J. Med. 356, 459-468 (2007).

27. Monte-Mór, B. C. R. \& Costa, F. F. A mutação JAK2 V617F e as síndromes mieloproliferativas. Rev. Bras. Hematol. Hemoter. 30, 241-248 (2008).

28. Cerquozzi, S. \& Tefferi, A. Blast transformation and fibrotic progression in polycythemia vera and essential thrombocythemia: a literature review of incidence and risk factors. Blood Cancer J. 5, e366e366 (2015).

29. Lavi, N. Calreticulin Mutations in Myeloproliferative Neoplasms. Rambam Maimonides Med. J. 5, e0035 (2014).

30. Ciboddo, M. \& Mullally, A. JAK2 (and other genes) be nimble with MPN diagnosis, prognosis, and therapy. Hematology 2018, 110-117 (2018).

31. Cabagnols, X. et al. Differential association of calreticulin type 1 and type 2 mutations with myelofibrosis and essential thrombocytemia: relevance for disease evolution. Leukemia 29, 249-252 (2015).

32. Pietra, D. et al. Differential clinical effects of different mutation subtypes in CALR-mutant myeloproliferative neoplasms. Leukemia 30, 431-438 (2016).

33. Elf, S. et al. Mutant Calreticulin Requires Both Its Mutant C-terminus and the Thrombopoietin Receptor for Oncogenic Transformation. Cancer Discov. 6, 368-381 (2016).

34. O'Sullivan, J. M. \& Harrison, C. N. JAK-STAT signaling in the therapeutic landscape of myeloproliferative neoplasms. Mol. Cell. Endocrinol. 451, 71-79 (2017).

35. Staerk, J. et al. An amphipathic motif at the transmembrane-cytoplasmic junction prevents autonomous activation of the thrombopoietin receptor. Blood 107, 1864-1871 (2006).

36. Levy, G. et al. MPL Mutations in Essential Thrombocythemia Uncover A Common Path of Activation with Eltrombopag Dependent on W491. Blood (2020) doi:10.1182/blood.2019003240.

37. Pikman, Y. et al. MPLW515L Is a Novel Somatic Activating Mutation in Myelofibrosis with Myeloid Metaplasia. PLoS Med. 3, e270 (2006).

38. Cabagnols, X. et al. Presence of atypical thrombopoietin receptor (MPL) mutations in triple-negative essential thrombocythemia patients. Blood 127, 333-342 (2016).

39. Varghese, L. N., Defour, J.-P., Pecquet, C. \& Constantinescu, S. N. The Thrombopoietin Receptor: Structural Basis of Traffic and Activation by Ligand, Mutations, Agonists, and Mutated Calreticulin. Front. Endocrinol. (Lausanne). 8, 59 (2017).

40. Aruch, D. \& Mascarenhas, J. Contemporary approach to essential thrombocythemia and polycythemia vera. Curr. Opin. Hematol. 23, 150-160 (2016).

41. Harrison, C. et al. JAK Inhibition with Ruxolitinib versus Best Available Therapy for Myelofibrosis. N. Engl. J. Med. 366, 787-798 (2012).

42. Ajayi, S. et al. Ruxolitinib. in 119-132 (2018). doi:10.1007/978-3-319-91439-8_6.

43. Spivak, J. L. Myeloproliferative Neoplasms. N. Engl. J. Med. 376, 2168-2181 (2017).

44. Pollak, M. Metformin and Other Biguanides in Oncology: Advancing the Research Agenda. Cancer Prev. Res. 3, 1060-1065 (2010). 
45. Neto, E. M. R. et al. Metformina: Uma Revisão da Literatura. Saúde e Pesqui. 8, 355-362 (2015).

46. Leverve, X. M. et al. Mitochondrial metabolism and type-2 diabetes: a specific target of metformin. Diabetes Metab. 29, 6S88-94 (2003).

47. Goodarzi, M. O. \& Bryer-Ash, M. Metformin revisited: re-evaluation of its properties and role in the pharmacopoeia of modern antidiabetic agents. Diabetes, Obes. Metab. 7, 654-665 (2005).

48. Dykens, J. A. et al. Biguanide-induced mitochondrial dysfunction yields increased lactate production and cytotoxicity of aerobically-poised HepG2 cells and human hepatocytes in vitro. Toxicol. Appl. Pharmacol. 233, 203-210 (2008).

49. Guidoni, C. M., Olivera, C. M. X., Freitas, O. de \& Pereira, L. R. L. Assistência ao diabetes no Sistema Único de Saúde: análise do modelo atual. Brazilian J. Pharm. Sci. 45, 37-48 (2009).

50. Pollak, M. N. Investigating Metformin for Cancer Prevention and Treatment: The End of the Beginning. Cancer Discov. 2, 778-790 (2012).

51. Owen, M. R., Doran, E. \& Halestrap, A. P. Evidence that metformin exerts its anti-diabetic effects through inhibition of complex 1 of the mitochondrial respiratory chain. Biochem. J. 348 Pt 3, 607-14 (2000).

52. Drahota, Z. et al. Biguanides inhibit complex I, II and IV of rat liver mitochondria and modify their functional properties. Physiol. Res. 63, 1-11 (2014).

53. Evans, J. M. M., Donnelly, L. A., Emslie-Smith, A. M., Alessi, D. R. \& Morris, A. D. Metformin and reduced risk of cancer in diabetic patients. BMJ 330, 1304-1305 (2005).

54. Higurashi, T. et al. Metformin for chemoprevention of metachronous colorectal adenoma or polyps in post-polypectomy patients without diabetes: a multicentre double-blind, placebo-controlled, randomised phase 3 trial. Lancet Oncol. 17, 475-483 (2016).

55. Paulus, J. K., Williams, C. D., Cossor, F. I., Kelley, M. J. \& Martell, R. E. Metformin, Diabetes, and Survival among U.S. Veterans with Colorectal Cancer. Cancer Epidemiol. Biomarkers Prev. 25, 14181425 (2016).

56. Zhou, G. et al. Role of AMP-activated protein kinase in mechanism of metformin action. J. Clin. Invest. 108, 1167-1174 (2001).

57. Yuan, P. et al. Phenformin enhances the therapeutic benefit of BRAFV600E inhibition in melanoma. Proc. Natl. Acad. Sci. 110, 18226-18231 (2013).

58. Sahra, I. Ben et al. The antidiabetic drug metformin exerts an antitumoral effect in vitro and in vivo through a decrease of cyclin D1 level. Oncogene 27, 3576-3586 (2008).

59. Liu, Z. et al. Phenformin Induces Cell Cycle Change, Apoptosis, and Mesenchymal-Epithelial Transition and Regulates the AMPK/mTOR/p70s6k and MAPK/ERK Pathways in Breast Cancer Cells. PLoS One 10, e0131207 (2015).

60. Guo, Z. et al. Phenformin inhibits growth and epithelial-mesenchymal transition of ErbB2overexpressing breast cancer cells through targeting the IGF1R pathway. Oncotarget 8, (2017).

61. Xu, G. et al. Metformin ameliorates ionizing irradiation-induced long-term hematopoietic stem cell injury in mice. Free Radic. Biol. Med. 87, 15-25 (2015).

62. Zhang, Q.-S. et al. Metformin improves defective hematopoiesis and delays tumor formation in Fanconi anemia mice. Blood 128, 2774 (2016).

63. Green, A. S. et al. The LKB1/AMPK signaling pathway has tumor suppressor activity in acute myeloid leukemia through the repression of mTOR-dependent oncogenic mRNA translation. Blood 116, 42624273 (2010).

64. Liang, X. et al. Effects of metformin on proliferation and apoptosis of human megakaryoblastic Dami and MEG-01 cells. J. Pharmacol. Sci. 135, 14-21 (2017). 
65. Malek, M. A. Y. A. et al. Molecular chaperone GRP78 enhances aggresome delivery to autophagosomes to promote drug resistance in multiple myeloma. Oncotarget 6, 3098-110 (2015).

66. Weroha, S. J. \& Haluska, P. The Insulin-Like Growth Factor System in Cancer. Endocrinol. Metab. Clin. North Am. 41, 335-350 (2012).

67. Veiga, S. R. et al. Phenformin-Induced Mitochondrial Dysfunction Sensitizes Hepatocellular Carcinoma for Dual Inhibition of mTOR. Clin. Cancer Res. 24, 3767-3780 (2018).

68. Fenerich, B. A. et al. The Pharmacological IGF1R-IRS1/2 Inhibitor NT157 Presents Multiple AntiNeoplastic Effects in Myeloproliferative Neoplasms. Blood 130, 1253-1253 (2017).

69. Campos, P. M. et al. IRS2 silencing increases apoptosis and potentiates the effects of ruxolitinib in JAK2V617F-positive myeloproliferative neoplasms. Oncotarget 7, 6948-6959 (2016).

70. Velez, J. et al. Biguanides sensitize leukemia cells to ABT-737-induced apoptosis by inhibiting mitochondrial electron transport. Oncotarget 7, 51435-51449 (2016).

71. Kuntz, E. M. et al. Targeting mitochondrial oxidative phosphorylation eradicates therapy-resistant chronic myeloid leukemia stem cells. Nat. Med. 23, 1234-1240 (2017).

72. Kawashima, I. \& Kirito, K. Metformin inhibits JAK2V617F activity in MPN cells by activating AMPK and PP2A complexes containing the B56 $\alpha$ subunit. Exp. Hematol. 44, 1156-1165.e4 (2016).

73. Machado-Neto, J. A. et al. Metformin exerts multitarget antileukemia activity in JAK2V617F-positive myeloproliferative neoplasms. Cell Death Dis. 9, 311 (2018).

74. Mead, A. J. \& Mullally, A. Myeloproliferative neoplasm stem cells. Blood 129, 1607-1616 (2017).

75. Quentmeier, H., MacLeod, R. A. F., Zaborski, M. \& Drexler, H. G. JAK2 V617F tyrosine kinase mutation in cell lines derived from myeloproliferative disorders. Leukemia 20, 471-476 (2006).

76. Uozumi, K. et al. Establishment and characterization of a new human megakaryoblastic cell line (SET2) that spontaneously matures to megakaryocytes and produces platelet-like particles. Leukemia $\mathbf{1 4}$, $142-152$ (2000).

77. Mullally, A. et al. Physiological Jak2V617F Expression Causes a Lethal Myeloproliferative Neoplasm with Differential Effects on Hematopoietic Stem and Progenitor Cells. Cancer Cell 17, 584-596 (2010).

78. Georgiades, P. et al. vavCre Transgenic mice: A tool for mutagenesis in hematopoietic and endothelial lineages. genesis 34, 251-256 (2002).

79. McKinnon, K. M. Flow Cytometry: An Overview. Curr. Protoc. Immunol. 120, (2018).

80. Morrison, S. J., Wandycz, A. M., Hemmati, H. D., Wright, D. E. \& Weissman, I. L. Identification of a lineage of multipotent hematopoietic progenitors. Development 124, 1929-39 (1997).

81. Koulnis, M. et al. Identification and Analysis of Mouse Erythroid Progenitors using the CD71/TER119 Flow-cytometric Assay. J. Vis. Exp. (2011) doi:10.3791/2809.

82. StemCell Technologies. Technical Manual: Humam Colony-Forming Unit (CFU) Assays Using MethoCultTM. in 52 (2019).

83. Andrade, J. et al. Effects of Sublethal Irradiation on Patterns of Engraftment after Murine Bone Marrow Transplantation. Biol. Blood Marrow Transplant. 17, 608-619 (2011).

84. Kaur, S. et al. Self-repopulating recipient bone marrow resident macrophages promote long-term hematopoietic stem cell engraftment. Blood 132, 735-749 (2018).

85. Barbier, V., Winkler, I. G., Wadley, R. \& Lévesque, J.-P. Flow Cytometry Measurement of Bone Marrow Perfusion in the Mouse and Sorting of Progenitors and Stems Cells According to Position Relative to Blood Flow In Vivo. in 45-63 (2012). doi:10.1007/978-1-61779-527-5_4.

86. Cheng, H., Liang, P. H. \& Cheng, T. Mouse Hematopoietic Stem Cell Transplantation. in 25-35 (2013). doi:10.1007/978-1-62703-317-6_3. 
87. Coelho-Silva, J. L. et al. Metformin Suppress Cellular and Molecular Processes Related to Maintenance and Proliferation of Myeloproliferative Neoplasm Stem Cell. Blood 134, 1682-1682 (2019).

88. Notta, F. et al. Isolation of Single Human Hematopoietic Stem Cells Capable of Long-Term Multilineage Engraftment. Science (80-. ). 333, 218-221 (2011).

89. Morrison, S. J. \& Weissman, I. L. The long-term repopulating subset of hematopoietic stem cells is deterministic and isolatable by phenotype. Immunity 1, 661-673 (1994).

90. Christensen, J. L. \& Weissman, I. L. Flk-2 is a marker in hematopoietic stem cell differentiation: A simple method to isolate long-term stem cells. Proc. Natl. Acad. Sci. 98, 14541-14546 (2001).

91. Yang, L. et al. Identification of Lin-Sca1+kit+CD34+Flt3- short-term hematopoietic stem cells capable of rapidly reconstituting and rescuing myeloablated transplant recipients. Blood 105, 27172723 (2005).

92. Langford, D. J. et al. Coding of facial expressions of pain in the laboratory mouse. Nat. Methods 7, 447-449 (2010). 
ANEXOS 


\section{ANEXO A - Aprovação do projeto de pesquisa pelo Comitê de Ética em Pesquisa do Hospital das Clínicas da Faculdade de Medicina de Ribeirão Preto da Universidade de São Paulo.}

USP - HOSPITAL DAS
CLÍNICAS DA FACULDADE DE Platoforma
MEDICINA DE RIBEIRÃO
PRETO DA USP -
PARECER CONSUBSTANCIADO DO CEP

\section{DADOS DO PROJETO DE PESQUISA}

Título da Pesquisa: Investigação do efeito da fenformina em neoplasias mieloproliferativas

Pesquisador: Fabíola Traina

Área Temática:

Versão: 1

CAAE: 16724319.7 .0000 .5440

Instituição Proponente: Hospital das Clínicas da Faculdade de Medicina de Ribeirão Preto da USP -

Patrocinador Principal: Financiamento Próprio

\section{DADOS DO PARECER}

Número do Parecer: 3.455 .210

\section{Apresentação do Projeto:}

Neoplasias mieloproliferativas (NMP) constituem um grupo de distúrbios hematológicos caracterizados por alterações moleculares na célula-tronco hematopoética, resultando em proliferação exacerbada de uma ou mais linhagens mieloides. A investigação de mutações nos genes JAK2, CALR e MPL compõem o algoritmo diagnóstico para as NMP, estando presentes em $95 \%$ dos pacientes, e resultam em ativação constitutiva da via JAK/STAT. As biguanidas incluem as drogas metformina, buformina e fenformina, que são compostos ativos hipoglicêmicos cujo potencial efeito antineoplásico vem sendo amplamente estudado. Recentemente, nosso grupo de pesquisa identificou que a metformina exerce efeitos antineoplásicos em modelos celulares de NMP e em modelo murino knockin para a mutação JAK2V617F. A fenformina é a biguanida mais potente, mas sua eficácia antineoplásica ainda não foi investigada para NMP, tampouco comparada com a exercida pela metformina. $O$ objetivo deste trabalho é investigar os efeitos antineoplásicos da fenformina em modelos de NMP JAK2V617F. Em camundongos knockin JAK2V617F, avaliaremos os efeitos in vivo e ex vivo do tratamento com fenformina no fenótipo neoplásico, quanto aos parâmetros hematológicos, ativação de vias de sinalização e capacidade de autorrenovação da célula tronco hematopoética. Em células primárias de pacientes com policitemia vera, avaliaremos o efeito do tratamento com fenformina in vitro na capacidade de formação de colônias eritroides independentes de eritropoietina. Os dados serão analisados através de comparações entre as médias dos grupos experimentais, utilizando os testes t-Student ou ANOVA, conforme

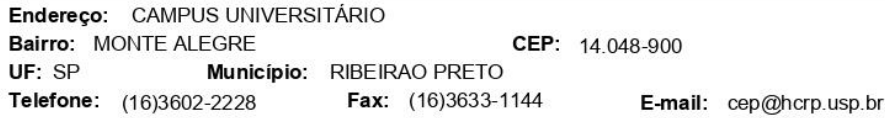




USP - HOSPITAL DAS
CLÍNICAS DA FACULDADE DE Olatoforma
MEDICINA DE RIBEIRÃO
PRETO DA USP -

Continuação do Parecer: 3.455 .210

apropriados. Todos testes utilizarão $=0,05$.

Objetivo da Pesquisa:

Objetivo Primário:

Investigação da eficácia terapêutica e dos mecanismos moleculares da fenformina em neoplasias mieloproliferativas.

Objetivo Secundário:

1. Investigar a eficácia e os mecanismos moleculares do tratamento in vivo com fenformina em camundongos knock-in JAKV617F:I- Avaliar os parâmetros hematológicos dos animais tratados ou não com fenformina;II- Quantificar os precursores eritroides na medula óssea e baço dos animais tratados ou não com fenformina;III- Estimar o percentual de células precursoras Lin-Sca-1+c-KitHi (LSK) e progenitores multipotentes;IV- Avaliar e comparar o comprometimento histopatológico do baço e medula óssea entre camundongos tratados ou não com fenformina;V- Analisar e comparar a expressão das vias de sinalização JAK2/STAT5, MAPK e PI3K/AKT/mTOR por citometria de fluxo em células de camundongos entre camundongos tratados ou não com fenformina.2. Avaliar a eficácia e os mecanismos moleculares do tratamento ex vivo com fenformina em células hematopoéticas de camundongos knock-in JAKV617F:IDeterminar a viabilidade celular e apoptose;Il- Analisar e comparar a expressão das vias de sinalização JAK2/STAT5, MAPK e PI3K/AKT/mTOR por citometria de fluxo;III- Analisar a capacidade de autorrenovação da célula-tronco hematopoética através de transplante alográfico com células tratadas ou não com fenformina.3. Avaliar o efeito do tratamento ex vivo com fenformina em células primárias de pacientes com PV:I. Avaliar a capacidade de formação de colônias eritroides independentes de eritropoietina.

Avaliação dos Riscos e Benefícios:

Riscos:

Para os pacientes incluídos no estudo, com relação a coleta de sangue periférico, há o incômodo da "picada" e há risco de uma pequena mancha arroxeada no local da punção; infecção no local da coleta de sangue pode acontecer muito raramente. A coleta de sangue de medula óssea será realizada durante a coleta de seus exames de rotina indicados pelo seu médico para tratamento da sua doença, a punção pra coleta de sangue de medula óssea será realizada na região posterior e superior da crista ilíaca ou pelve, sob anestesia local. A coleta de sangue de medula óssea é um procedimento invasivo que pode causar dor, desconforto e complicações relacionadas a procedimentos invasivos, como sangramento e infecções.

Endereço: CAMPUS UNIVERSITÁRIO Bairro: MONTE ALEGRE

UF: SP Município: RIBEIRAO PRETO

Telefone: (16)3602-2228 Fax: (16)3633-1144

CEP: $14.048-900$ 


USP - HOSPITAL DAS
CLÍNICAS DA FACULDADE DE Platoforma
MEDICINA DE RIBEIRÃO
PRETO DA USP -

Continuação do Parecer: 3.455 .210

Benefícios:

Este projeto não trará nenhum benefício imediato para o participante do estudo e este pode recusar-se a participar da pesquisa ou mesmo retirar o seu consentimento em qualquer fase da mesma, sem penalização alguma e sem prejuízo ao seu cuidado e tratamento.

Comentários e Considerações sobre a Pesquisa:

Projeto bem escrito, com objetivo claro e metodologia adequada.

Considerações sobre os Termos de apresentação obrigatória:

TCLE apresentado e de acordo com as normas vigentes.

Recomendações:

Não se aplica.

Conclusões ou Pendências e Lista de Inadequações:

Aprovado Diante do exposto e à luz da Resolução CNS 466/2012, o projeto de pesquisa, assim como o Termo de Consentimento Livre e Esclarecido versão versão 1 data 01/07/2019, podem ser enquadrados na categoria APROVADO.

Considerações Finais a critério do CEP:

Projeto Aprovado: Tendo em vista a legislação vigente, devem ser encaminhados ao CEP, relatórios parciais anuais referentes ao andamento da pesquisa e relatório final ao término do trabalho. Qualquer modificação do projeto original deve ser apresentada a este CEP em nova versão, de forma objetiva e com justificativas, para nova apreciação.

Este parecer foi elaborado baseado nos documentos abaixo relacionados:

\begin{tabular}{|l|l|c|l|c|}
\hline \multicolumn{1}{|c|}{ Tipo Documento } & \multicolumn{1}{|c|}{ Arquivo } & Postagem & Autor & Situação \\
\hline Informações Básicas & PB_INFORMAÇÕES_BÁSICAS_DO_P & $03 / 07 / 2019$ & & Aceito \\
do Projeto & ROJETO_1347016.pdf & $15: 10: 14$ & \\
\hline TCLE / Termos de & TCLE_Pacientes_NMP_Fenformina_V1. & $03 / 07 / 2019$ \\
$15: 09: 53$ & NATASHA PEIXOTO & Aceito \\
Assentimento / & Fdf & & & \\
Justificativa de & & & \\
Ausência & & $03 / 07 / 2019$ & NATASHA PEIXOTO & Aceito \\
\hline $\begin{array}{l}\text { Projeto Detalhado / } \\
\text { Brochura } \\
\text { Investigador }\end{array}$ & Projeto_NMP_Fenformina.pdf & $14: 29: 01$ & FONSECA & \\
\hline Cronograma & Cronograma_NMPFenformina.pdf & $28 / 06 / 2019$ & NATASHA PEIXOTO & Aceito \\
\hline Orçamento & Orcamentodetalhado_NMPFenformin & $28 / 06 / 2019$ & NATASHA PEIXOTO & Aceito \\
\hline
\end{tabular}

Endereço: CAMPUS UNIVERSITÁRIO Bairro: MONTE ALEGRE CEP: $14.048-900$

UF: SP Municipio: RIBEIRAO PRETO

Telefone: (16)3602-2228 Fax: (16)3633-1144 E-mail: cep@hcrp.usp.br 


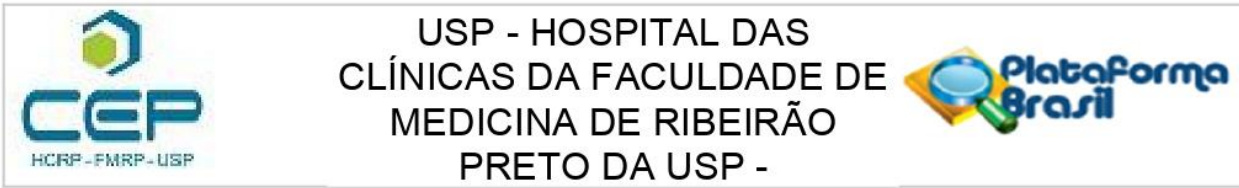

Continuação do Parecer: 3.455 .210

\begin{tabular}{|l|l|c|l|c|}
\hline Orçamento & a.pdf & $16: 29: 41$ & FONSECA & Aceito \\
\hline Orçamento & AprovacaoOrcamentoUPC_NMPFenfor & $28 / 06 / 2019$ & $\begin{array}{l}\text { NATASHA PEIXOTO } \\
\text { mina.pdf }\end{array}$ & Aceito \\
\hline Folha de Rosto & FolhaRosto_Fenformina.pdf & $28 / 06 / 2019$ \\
& & $\begin{array}{l}\text { NATASHA PEIXOTO } \\
\text { FONSECA }\end{array}$ & Aceito \\
\hline
\end{tabular}

Situação do Parecer:

Aprovado

Necessita Apreciação da CONEP:

Não

RIBEIRAO PRETO, 15 de Julho de 2019

Assinado por:

MARCIA GUIMARÃES VILLANOVA

(Coordenador(a))

Endereço: CAMPUS UNIVERSITÁRIO

Bairro: MONTE ALEGRE

CEP: $14.048-900$

UF: SP Municipio: RIBEIRAO PRETO

Telefone: (16)3602-2228 Fax: (16)3633-1144 E-mail: cep@hcrp.usp.br

Página 04 de 04 


\section{ANEXO B - Aprovação do projeto de pesquisa pelo Comitê de Ética no Uso de Animais da Faculdade de Medicina de Ribeirão Preto da Universidade de São Paulo (Protocolo 183/2018).}

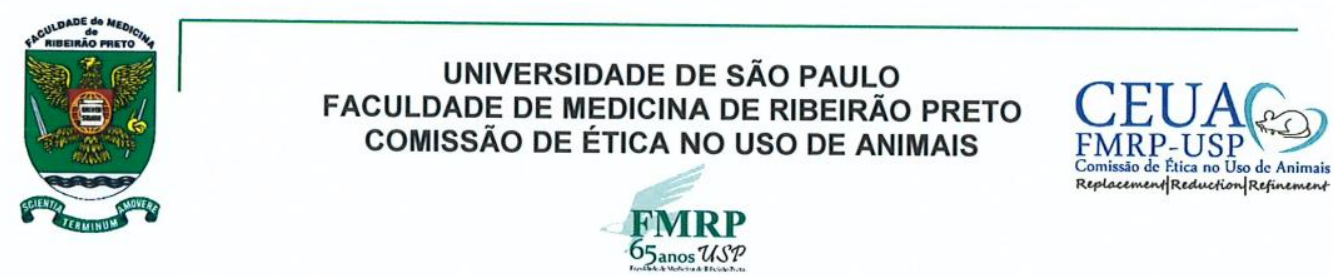

\section{E R T I F I C A D O}

Certificamos que o Protocolo intitulado "Investigação do efeito da fenformina em neoplasias mieloproliferativas", registrado com o número 183/2018, sob a responsabilidade da Profa. Dra. Fabíola Traina, envolvendo a produção, manutenção ou utilização de animais pertencentes ao filo Chordata, subfilo Vertebrata (exceto humanos) para fins de pesquisa científica, encontra-se de acordo com os preceitos da Lei $n^{\circ} 11.794$ de 8 de outubro de 2008, do Decreto n 6.899 de 15 de julho de 2009 e com as normas editadas pelo Conselho Nacional de Controle de Experimentação Animal (CONCEA), e foi APROVADO pela Comissão de Ética no Uso de Animais da Faculdade de Medicina de Ribeirão Preto da Universidade de São Paulo em reunião de 28 de janeiro de 2019.

Este Protocolo prevê a utilização de 8 camundongos JAK2 WT/WTVav/Cre fêmeas pesando 22g, 8 camundongos JAK2WT/Fl - Vav/Cre fêmeas pesando 22g e 53 camundongos C57BL/6J PEP/Boy fêmeas pesando $22 \mathrm{~g}$ oriundos do Laboratório de Estudos Experimentais em Animais. Vigência da autorização: 28/01/2019 a 10/01/2024.

We certify that the Protocol $n^{o} 183 / 2018$, entitled "Investigation of the effect of phenformin in myeloproliferative neoplasms", is in accordance with the Ethical Principles in Animal Research adopted by the National Council for Control of Animal Experimentation (CONCEA) and was approved by the Local Animal Ethical Committee from Ribeirão Preto Medical School of the University of São Paulo in 01/28/2019. This protocol involves the production, maintenance or use of animals from phylum Chordata, subphylum Vertebrata (except humans) for research purposes, and includes the use of 8 female JAK2 WT/WT- Vav/Cre mice weighing 22g, 8 female JAK2WT/FI - Vav/Cre mice weighing 22g and 53 female C57BL/6J PEP/Boy mice weighing $22 \mathrm{~g}$ from the Laboratory of Experimental Animal Studies. This certificate is valid until $01 / 10 / 2024$.

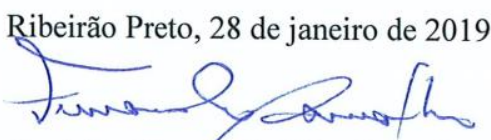

Prof. Dr. Fernando Silva Ramalho Coordenador da CEUA-FMRP - USP 